\title{
The importance of thermal modelling and prototyping in shelter design
}

\section{Transforming shelter design for the displaced}

D. Fosas *,a, F. Moran ${ }^{\text {a }}$, S. Natarajan ${ }^{\text {a }}$, J. Orr ${ }^{\text {b }}$, D. Coley ${ }^{\text {a }}$

${ }^{a}$ Department of Architecture and Civil Engineering, University of Bath, Bath, UK

${ }^{\mathrm{b}}$ Department of Engineering, University of Cambridge, England, UK

\begin{abstract}
More than 9 million people live in shelters globally, often in extremely hot climates. The thermal performance of shelters is often overlooked in the design process, despite being a consideration second only to safety in surveys of camp dwellers. Indeed, indoor temperatures exceeding $40{ }^{\circ} \mathrm{C}$ have been recorded in previous studies. To aid in improving conditions, the roles building simulation and prototyping could play in forecasting shelter thermal performance as part of a new shelter design process are examined. The thermal performance of prototypes, built in the refugee camp of Azraq, was monitored during the hot season to evaluate four design approaches: (1) "blind" (uncalibrated) models, (2) calibrated models, (3) on-site design-variants and (4) off-site prototypes. These included the original shelter and six design alternatives implementing different overheating countermeasures. The results demonstrate that blind models are sensitive to the judgement of uncertainties but were still qualitatively useful. Model calibration vastly improves the agreement and significantly enhances forecasts of performance for the design alternatives, which remained similar across examined climates. It is therefore concluded that simulation and prototyping, either on-site or off-site, should be adopted within the shelter design process before mass deployment, to create better living conditions for their dwellers.
\end{abstract}

Keywords: shelter, design, prototyping, building simulation, calibration, overheating 


\section{Introduction}

The United Nations High Commissioner for Refugees (UNHCR) is currently interested in the protection of more than 71 million people worldwide, a figure that includes nearly 20 million refugees and 39 million internally displaced (2019b; UNHCR 2017a). As natural disasters and conflicts force large migrations, those affected need urgent accommodation for an unknown period of time. The response to these crises varies according to the context but just within the population of concern to the UNHCR, there are 9.5 million living in shelters at the moment ${ }^{1}$.

Shelters in managed and UNHCR-assisted camps are conceived as temporary solutions to rapid displacement and are established through the collaboration between the local government and aid agencies. Although there is no clear definition of temporary, the assumption is: approximately 1 year for emergency, 4 years for transitional shelters, and 10 years or more for durable and permanent shelter solutions (Félix et al. 2013; UNHCR 2016). Transitional shelters are a mid-term affordable measure that are not as vulnerable as the tents deployed during the emergency stage, nor signify the permanence of the other solutions; the latter being a key consideration for the governments of the hosting countries.

This work focuses on transitional shelters because past experiences demonstrate they remain in use for many years, becoming a semi-permanent solution (Albadra et al. 2018). Due to logistical, economic and political considerations, institutional agents favour shelters that are lightweight, dismountable and low-cost, paying less attention to their thermal performance (Albadra et al. 2018). For example, the Syrian refugee camp of Azraq in Jordan had to be built at a rate of 100 transitional shelters a day for more than 4 months to house the increasing number of refugees in the country (UNHCR pers. comm.). Each of these lightweight shelters had an estimated cost of \$2300 in Jordan in 2013 and could be built under 16 hours by a team of 4 people (UNHCR 2016). Similarly, 723,000 refugees from Myanmar arrived in Bangladesh over a 4-month period in 2017, all requiring shelter at an average of 6,000 people per day (UNHCR 2019a).

Concerns have been voiced regarding the indoor thermal environments these shelters deliver and the potential effects on comfort, health and well-being for their occupants (Cornaro et al. 2015; Albadra et al. 2017; Fosas, Albadra, et al. 2018). The initial shelters provided by humanitarian agencies, whilst offering protection from the elements, may not be effective enough against the climate at the location in question, which is often aggressive (Figure 1). The potential indoor heat stress can be estimated with Steadman's Apparent Temperature for indoor environments, which combines the effect of air temperature and relative humidity in a shaded environment protected from wind (Steadman 1979a; Steadman 1979b; Steadman 1984). The metric is in degree Celsius and scales linearly with thermal stress. An Apparent Temperature of $25{ }^{\circ} \mathrm{C}$ represents comfortable conditions and $36{ }^{\circ} \mathrm{C}$ represents severe heat stress. Empirical studies have supported this hypothesis for shelters in camps such as Azraq in Jordan (Albadra et al. 2017), Hitsats in Ethiopia (Paszkiewicz \& Fosas 2019) and Kutupalong in Bangladesh through preliminary field work conducted by the authors, with air temperatures greater than $40{ }^{\circ} \mathrm{C}$ being measured inside shelters at these locations.

\footnotetext{
${ }^{1}$ Authors' estimate from the 8.7 million living in shelters by the end of 2016 (UNHCR 2017b) and the 0.8 million that arrived since to Bangladeshi camps as of May 2019 (UNHCR 2019a).
} 


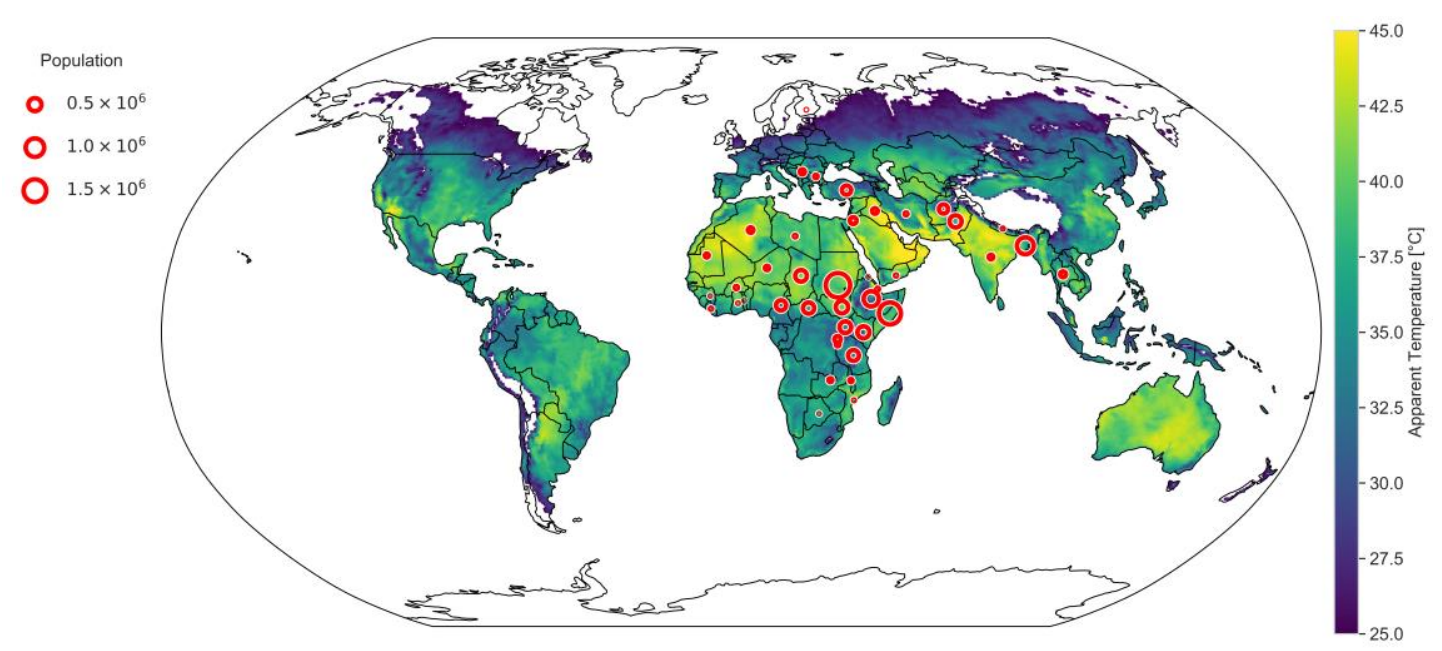

Figure 1: UNHCR people of concern living in shelters and heat stress in 2017 (total population of 9.5 million, aggregated to hosting country (UNHCR 2019a; 2019b); Apparent Temperature for indoor environments as per Steadman (1979a; 1979b; 1984); map constructed using environmental parameters from NASA (Gelaro et al. 2017) for the 99th percentile of maximum annual temperatures; Apparent Temperature reported for values above $25{ }^{\circ} \mathrm{C}$ and clipped to $45^{\circ} \mathrm{C}$ )

This begs the question, how might such situations be avoided? In each setting the design space will be restricted by the material palette, the attitudes of the local government, money, and time. For those designing off-the-shelf solutions for mass dispatch from warehouses, the time constraint is less; as it will also be in camps where the displaced are initially housed in emergency tents. This suggests that in such situations, a modest period of design work could be entertained, and one element of this could look at the thermal conditions inside the shelter and offer improvements. For example, increased ventilation pathways, or the suggestion to use insulation.

One avenue to make informed design decisions about the thermal performance of transitional shelters is building simulation, an aspect known to be overlooked in the current shelter design process (The Sphere project 2011; Corsellis 2012). Among the options available, physics-based building simulations (also termed white-box models) would seem apt since their implementation of heat and mass transfers laws is particularly suited to evaluating new designs (Clarke \& Hensen 2015; Clarke 2001). However, a key barrier for their adoption is that it is unknown if accurate predictions can be made in this context. Apart from the well-known challenges for white-box building simulation in predicting thermal performance in conventional buildings (de Wilde 2014; Mantesi et al. 2018; de Wit \& Augenbroe 2002), the fact that transitional shelters are hastily built to unknown qualities, and their reliance on passive strategies like natural ventilation, add further complexity (Cornaro et al. 2015; Fosas, Albadra, et al. 2018). Many of the parameters such as the air tightness or true U-values of cavity walls, which are critical to successful simulation, are likely to be unknown and hence potentially undermine any possible benefit gained from simulation. Yet, transitional shelters are mass-produced and comparatively simpler than conventional buildings, where simulation is routinely used (Hamilton et al. 2017; Deru et al. 2011; Kavgic et al. 2010; Swan \& Ugursal 2009; Taylor et al. 2016). This suggests the potential for a highly favourable cost to benefit ratio: the additional work needed to undertake simulation is likely to be small against the scale of positive impact on dwellers resulting from a thermally improved shelter design.

Another possibility is to prototype shelters on-site, where an initial design is constructed, monitored, then possibly adjusted. However, prototypes are likely to be created in a climate remote from their intended destination, a common situation in the case of off-the-shelf solutions. Simulation could then play a role in allowing the shelter to be moved in the software to any location in the world, with the initial monitoring being used to calibrate the model. This is termed here "off-site prototyping". 
Despite the importance of the thermal performance of shelters, there is a limited number of studies in the literature. Overall approaches to site selection and analyses are offered by Corsellis (2001) and Potangaroa \& Hynds (2008), but given the mass-production of shelters, the focus of this study is on the shelters themselves. Studies have mostly focused on the thermal performance of emergency tents in cold climates, according to the recent displacement experiences at the time (Manfield et al. 2004; Pöschl 2016). For example, Crawford et al. (2005) analysed two tent prototypes developed at Cambridge under laboratory conditions inside a freezer to characterize their thermal behaviour. This forms the basis of a calibrated model that is then simulated in selected locations in the world. Cornaro et al. (2015) performed a similar exercise for another emergency tent powered by solar energy in Italy (temperate climate). Using the calibrated model to assess design improvements for cold and hot conditions based on increased insulation and an ideal load heater and cooler, they showed that the passive performance of the tent could be little improved for hot season conditions. Obyn et al. (2015) studied the thermal performance of the standard family tent deployed by aid-agencies, questioning the extent to which building simulation could reproduce performance of this lightweight semi-translucent structure. Yu et al. (2016) studied the night-time performance of bamboo shelters and proposed construction variants based on their thermal performance in scale models during the cold season. On the other side of the spectrum, it has also been of interest the energy performance of durable shelter solutions like those in Haití (Borge-Diez, Colmenar-Santos, Pérez-Molina, et al. 2013; Borge-Diez, Colmenar-Santos, MurPérez, et al. 2013). However, such solutions fall beyond the scope of this study given they are closer to regular housing solutions than temporal ones.

Overall, even fewer studies deal with the simulation of temporal shelters, all of which focus on emergency tents (Crawford et al. 2005; Cornaro et al. 2015; Obyn et al. 2015). Of these studies, only Obyn et al. (2015) focus explicitly on the agreement between simulation and experimental results, assuming full knowledge of design specification and construction. Here, the $95 \%$ confidence intervals of indoor temperatures are reported to be within $2{ }^{\circ} \mathrm{C}$ for their control case in Brussels. Replicas in Burkina Faso and Luxembourg increase to $4.5{ }^{\circ} \mathrm{C}$ and $5.6{ }^{\circ} \mathrm{C}$, respectively. Like the other studies, they make active use of all the monitored data to manually arrive at a single model that is considered to best represent observations, being uncertain who well the model performs for unseen data not used as part of the calibration process, let alone design variants. In this case, calibration involved wind pressure coefficients (generated through simulation) and soil thickness (assuming a constant ground temperature). The methodological recommendations for modelling are of unknown validity considering the challenges in replicating the thermal behaviour of interconnected air cavities with respect to, for instance, simpler single-zone models with the same accuracy. This could be a contributing factor to the limited extent to which the model responds to night-time overcooling, as judged by the authors.

Aid agencies already work under pressure and with scarce resources to meet the needs of the displaced. An evidence-based account of the merits of building simulation needs to be established before they can rely on its predictions to deliver safer thermal indoor environments, especially in transitional shelters given their lifespan. The envisaged use of simulation in this context is to forecast performance of models based exclusively on expert-judgement or assisted by the monitored performance of a design prototype during the emergency stage of a crisis. This study therefore evaluates if forecasting indoor thermal conditions in transitional shelters is a tractable problem through building simulation and how it compares to experimental observations of shelter prototypes. Therefore, the objectives are to evaluate:

1. Whether simulated models based on design specification and expert judgement (termed here blind models) alone can predict the as-built thermal performance of transitional shelters;

2. The extent to which models calibrated against the observed performance of a built prototype improve predictions of simulated thermal performance; 
3. How well predictions of thermal performance of design variants based on the simulation of blind and calibrated models relate to observed thermal performance;

4. Whether shelter solutions can be prototyped in a different climatic context to that in which it is intended to be used at, and the role building simulation can play in this scenario.

The paper is organised as follows. First, the materials and methods are introduced, which presents (1) the as-built shelter prototypes considered, (2) the experimental conditions and data collection, (3) the different simulation models that attempt to replicate observed performance, and (4) the analysis techniques used. Next, results are presented according to each of the objectives of the study namely blind models, calibrated models, design alternatives and off-site prototyping. Lastly, the discussion of the results and the overall conclusions are presented.

\section{Materials and methods}

To evaluate the potential benefits of prototyping and simulation models at the design stage of a shelter solution, the real performance of prototypes against their modelled counterparts is compared, judging at every stage if the simulation-based approach adequately represents the real performance of the prototype (Table 1). Mapping to the objectives, the outline of the devised method is as follows:

1. Scope: A relevant case is selected. This comprises a pre-established transitional shelter (control) and the location where it is intended to be deployed.

2. Stage 1 - Control shelter prototype versus blind models:

a. The shelter prototype is built and monitored to capture its thermal performance.

b. Blind models of the shelter are created based on the design documentation and simulated under the same experimental weather conditions.

c. The simulated thermal performance of the blind models is compared to that of the control prototype.

3. Stage 2 - Control shelter prototype versus calibrated models:

a. The blind models from Stage 1 are trained with the first $70 \%$ of the monitored data that characterizes thermal performance of the shelter prototype to produce a calibrated model.

b. The calibration is then validated with the last $30 \%$ of the data.

c. The simulated thermal performance of the calibrated model is compared to that of the control prototype.

4. Stage 3 - Design alternative prototypes versus simulations based on the control model:

a. Several design alternatives for the control shelter are established.

b. Prototypes of these design alternatives are built and monitored to capture their thermal performance.

c. Two types of models are built for each design alternative, one based on the blind models for the control shelter (Stage 1) and another based on the calibrated one (Stage 2). The only modifications to these models are the changes introduced by the design alternatives, preserving every other aspect.

d. The thermal performance of each type of model is compared to that of the prototype.

5. Stage 4 - Ranking of models for design alternatives in different climates:

a. Use the models obtained in Stage 3 and simulate them under the climate they were devised for and a different climate in which they are assumed to be prototyped at.

b. Rank the performance of every model in each climate against a chosen baseline.

c. Compare the consistency of the rankings obtained across climates. 
Table 1: Study overview (n.b. models are here referred to physics-based models, also termed white-box models)

Can physics-based models be used to inform the thermal design of transitional shelters?

\begin{tabular}{lll}
\hline Objective & Approach & Method \\
\hline $\begin{array}{l}\text { 1) Evaluate whether simulated } \\
\text { models based on design }\end{array}$ & $\begin{array}{l}\text { Build and monitor a shelter } \\
\text { prototype on-site. Then }\end{array}$ & $\begin{array}{l}\text { Monitor indoor air temperature } \\
\text { at the centre of the room. }\end{array}$ \\
$\begin{array}{l}\text { judgement (termed here blind } \\
\text { models) alone can predict the }\end{array}$ & $\begin{array}{l}\text { using only information that } \\
\text { would be available to a third- }\end{array}$ & $\begin{array}{l}\text { Replicate in simulation model } \\
\text { considering educated guesses } \\
\text { for unknown parameters, }\end{array}$ \\
$\begin{array}{l}\text { as-built thermal performance } \\
\text { of transitional shelters. }\end{array}$ & $\begin{array}{l}\text { party. Compare differences in } \\
\text { performance. }\end{array}$ & $\begin{array}{l}\text { accounted for by single and } \\
\text { range estimates. Compare } \\
\text { differences in binned air } \\
\text { temperature histogram and } \\
\text { goodness-of-fit metrics. }\end{array}$ \\
& &
\end{tabular}

2) Appraise the extent to which Build and monitor a shelter models calibrated against the observed performance of a built prototype improve predictions of simulated thermal performance. prototype on-site. Then replicate in a white-box model using design specifications. Use calibration and validation as part of the model development by using the monitored data. Compare differences in performance.
Monitor indoor air temperature at the centre of the room. Replicate in simulation model, developed through formal calibration and validation procedure. Establish model with the best estimates for unknown parameters. Compare differences in binned air temperature histogram and goodness-of-fit metrics.

3) Compare how well predictions of thermal performance of design variants based on the simulation of blind and calibrated models relate to observed thermal performance.
Build and monitor shelter design variants on-site. Then replicate in white-box models based on blind and calibrated simulations. Compare differences in performance.
Select and build shelter design variants leveraging passive strategies. Monitor indoor air temperature at the centre of the room. Replicate in simulation model based on those developed for objectives 1 and 2. Compare differences in binned air temperature histogram and goodness-of-fit metrics.

\footnotetext{
4) Judge whether shelter solutions can be prototyped in a different climatic context to that in which it is intended to be used at, and the role building simulation can play in this scenario.
}
Rank the thermal performance of shelters and their design variants in the climate where their use is intended and another climate in which they might have been prototyped. Assess the consistency of the ranking in the two locations.
Select calibration-based model developed for objective 3 and rank their performance according to normalised goodness-of-fit metrics. Compare their correlation to the ranking obtained for those models in a different climatic zone. 
Since the population of concern is concentrated in countries with severe hot conditions (Figure 1), the focus is on overheating during the hot season in the Middle East for the case study, where the Syrian refugee camp of Azraq is selected (Jordan, $31.90^{\circ} \mathrm{N}, 36.58^{\circ} \mathrm{E}$, Figure 2). Established in 2014, it is the largest refugee camp of the country, hosting 40,615 people in 8,952 shelters as of December 2018 (Yacout, Almomani \& UNHCR 2018). It has been regarded by camp authorities as one of the world's best camps in terms of planning, structure and overall management, considering that it was pre-planned and mindful of the shortcomings perceived by care-givers in the older neighbouring camp of Zaatari (Dalal et al. 2018).

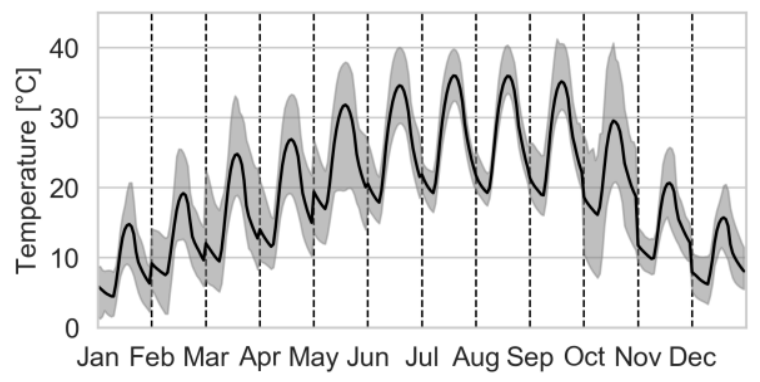

a) Dry bulb temperature

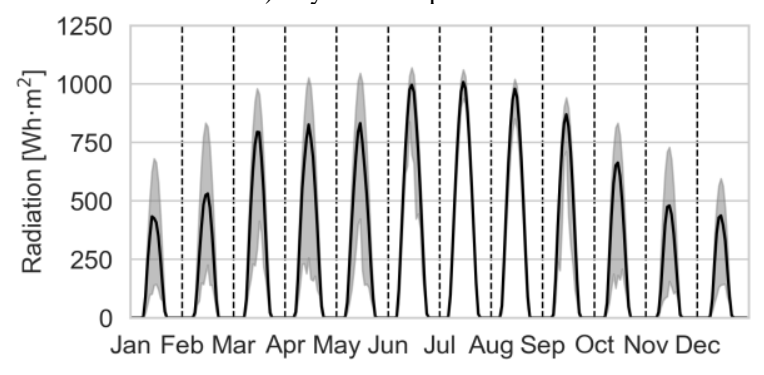

c) Global horizontal radiation

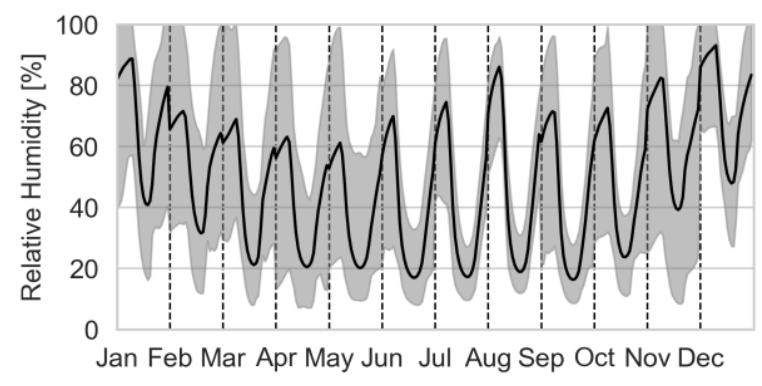

b) Relative humidity

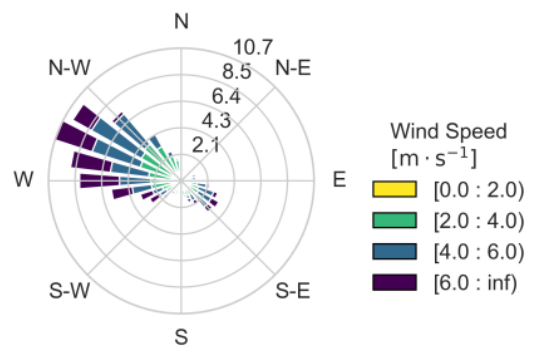

d) Windrose (orientation referenced to wind origin)

Figure 2: Weather at Azraq (year 2018; black: hourly average for month; grey: hourly max/min range for month; hot arid climate (BWh) according to the Köppen-Geiger climate classification (Kottek et al. 2006); data source: see section §2.2)

The next subsection presents all the shelter variants considered in this study. This includes the original shelter designed by UNHCR Jordan and selected design alternatives. This is followed by the description of experimental conditions and the data collection plan and the corresponding definition of thermal simulation models. Lastly, the analysis used to compare the real performance to the simulated ones and the criteria to evaluate what constitutes an acceptable agreement between them is described. It also presents the analysis method to judge if the performance of a shelter prototyped in a different climate can be extrapolated to that of the one where it is intended to be used at.

\subsection{Shelters}

The control shelter and six design alternatives were selected for this study (Figure 4). These were built in a secure compound in Azraq camp (Figure 3). This compound houses 12 shelters that were built at the same time and by the same team of builders as the rest of the camp and are consequently considered representative.

The seven shelters under consideration are here referred to as prototypes because they would be so at the design stage of shelter solutions. Their goal within the proposed design framework would be to have a proof-of-concept of their thermal performance. Six of these were retrofitted with different strategies aimed at delivering thermally safe indoor environments based on the work by Fosas, Albadra et al. (2018). That study considered a number of passive design strategies based on their suitability to reduce 
overheating for the climate at hand and reported shortcomings in the current shelter solution by their occupants. The overheating countermeasures considered did not hinder the thermal performance of the shelter during the cold season. Drawing on the major influences on performance identified, strategies examined here are increased insulation, thermal mass, ventilation, shading and their combinations. These design alternatives do not necessarily represent the views of what UNHCR Jordan nor the authors would consider apt for final use. Like in the previous study, the main requirement by camp authorities was that external appearance of shelters and underlying structure remained the same. In addition, options that could inform the retrofit strategy for shelters already deployed were prioritized. One shelter was maintained in its original form as a control to establish the baseline of thermal performance.

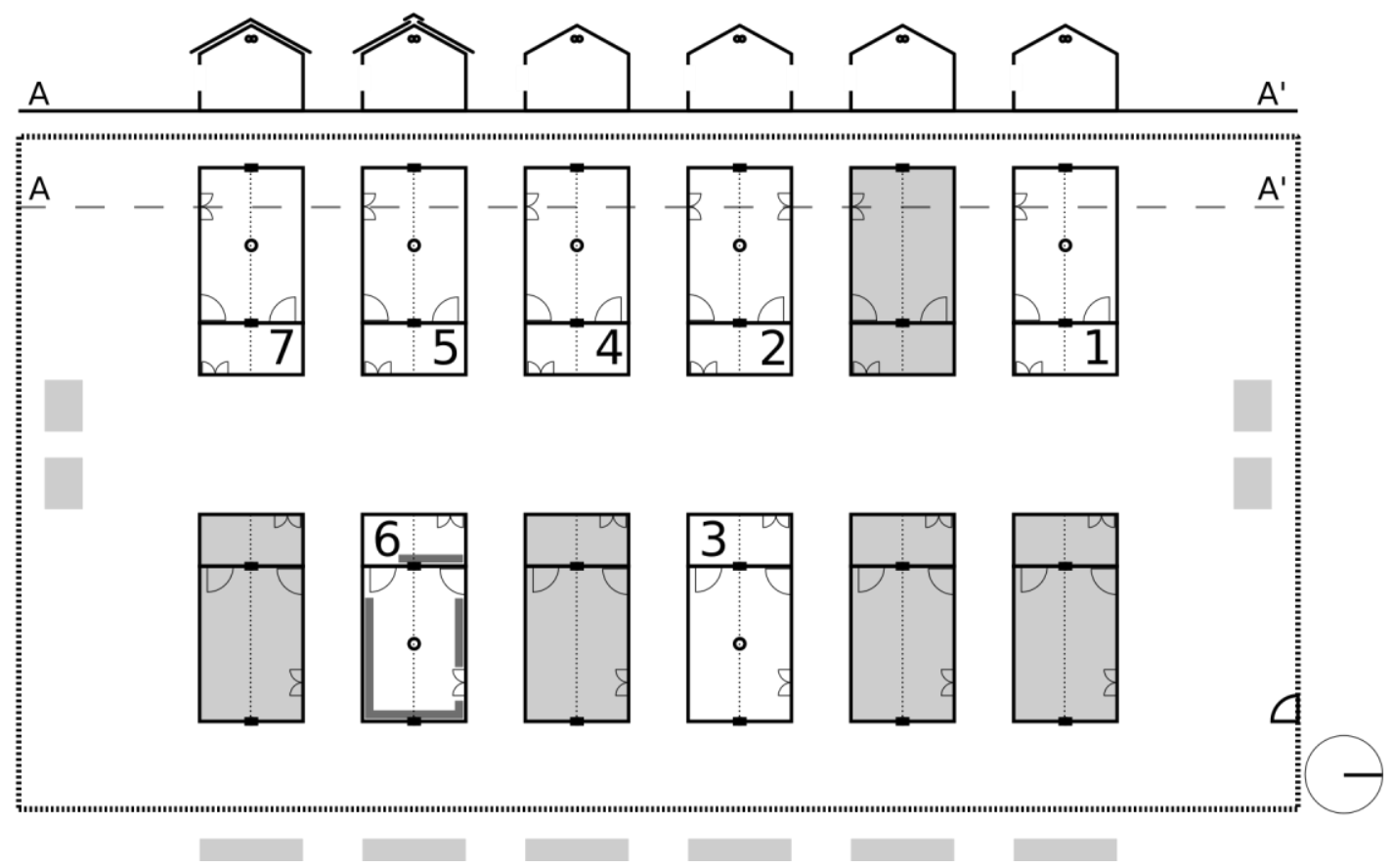

Figure 3: Compound shelter layout (refugee camp of Azraq in Jordan, internal address V02/B11/P13; see shelter overview in Figure 4; circle indicates internal sensor location; greyed fill indicates shading from surrounding objects, including other shelters not used in this study) 


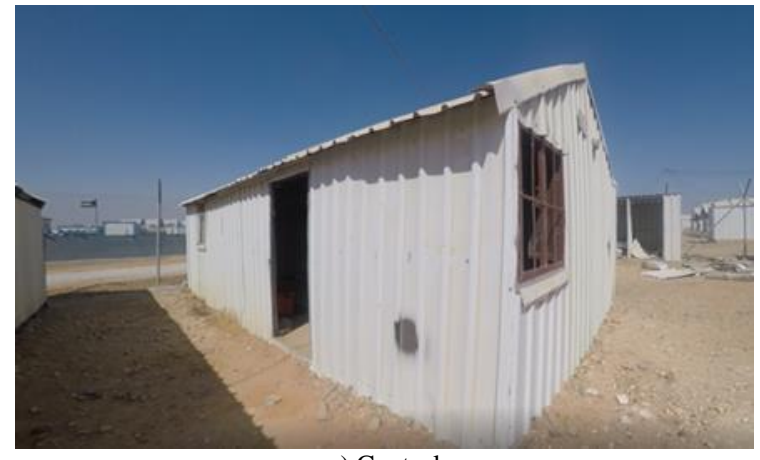

a) Control

(ID 1; Original T-Shelter at Azraq by UNHCR; outdoors view)

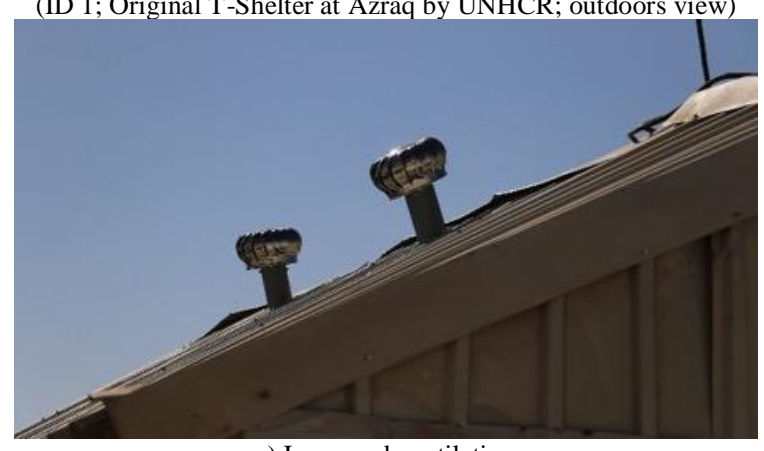

c) Increased ventilation

(ID 2; 4 high and low-level vents each and additional window)

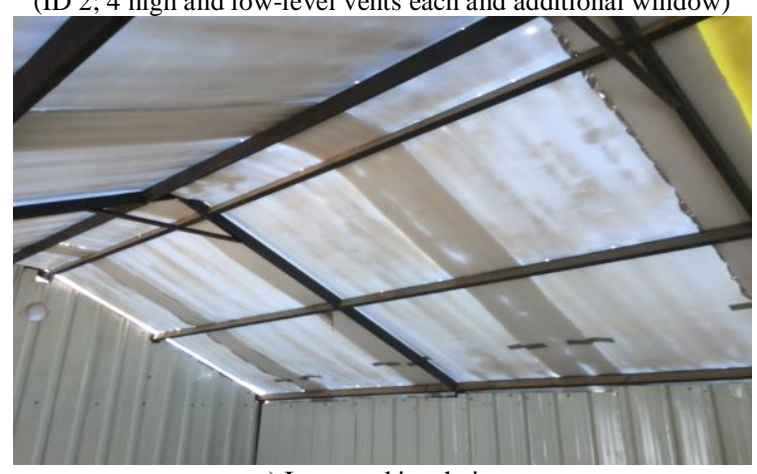

e) Increased insulation

(ID 4; doubled insulation and removal of thermal bridges)

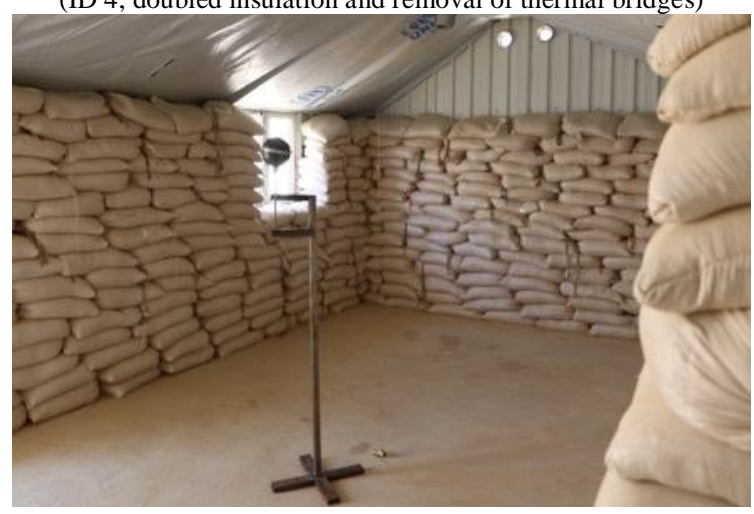

g) Thermal mass with internal sandbags (ID 6; Internal wall layer of $250 \mathrm{~mm}$ )



b) Control

(ID 1; Original T-Shelter at Azraq by UNHCR; indoors view)

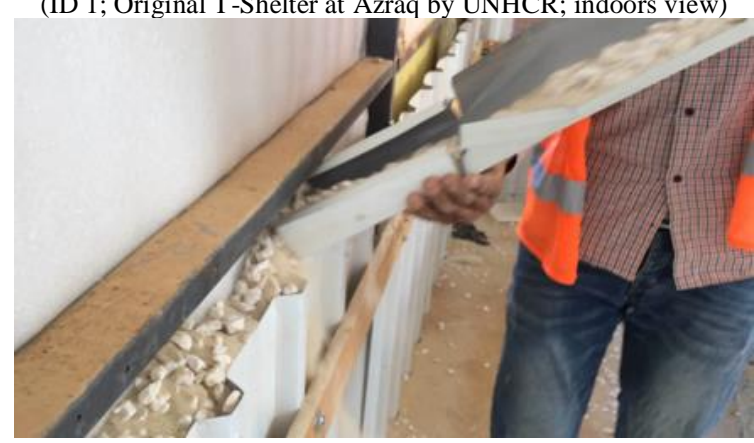

d) Thermal mass by cavity fill

(ID 3; $60 \mathrm{~mm}$ sand and gravel mix in wall cavity)

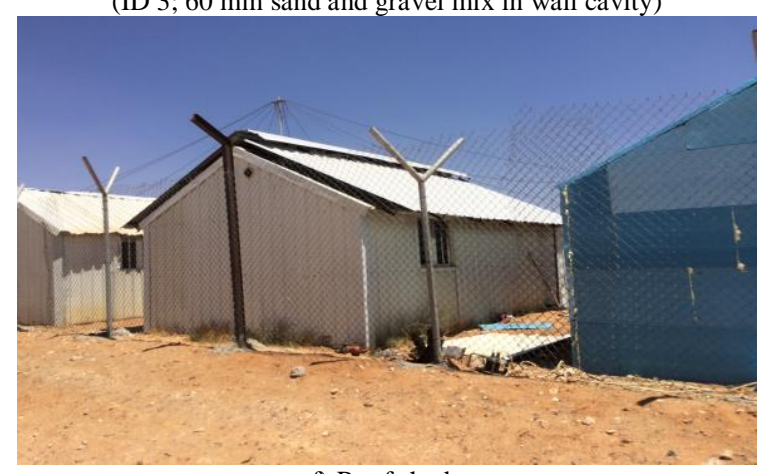

f) Roof shade

(ID 5; $150 \mathrm{~mm}$ above existing roof and increased overhang)

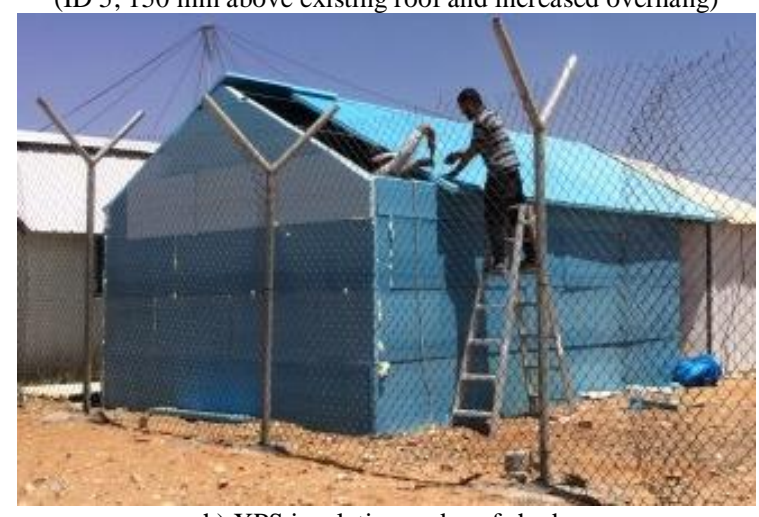

h) XPS insulation and roof shade

(ID 7; $40 \mathrm{~mm}$ insulation and roof shade with increased overhang)

Figure 4: Shelter prototypes in the experimental compound (refugee camp of Azraq in Jordan in August 2018, internal address V02/B11/P13; see location in Figure 3) 


\subsubsection{Control}

This is the Azraq T-Shelter as implemented by UNHCR after a public design competition in 2013 (Figure 4-a, Figure 4-b). The shelter comprises a $60 \mathrm{~mm} \times 30 \mathrm{~mm}$ steel frame structure anchored to the ground with shallow ground plates. The frame is covered with sheets of $15 \mathrm{~mm}$ foil faced expanded foam insulation and clad externally with a $0.35 \mathrm{~mm}$ Inverted Box Rib (IBR) steel panel. The walls are also clad internally with the same IBR panels. A tarpaulin is fixed to the underside of the roof to provide a ceiling. The internal floor is an uninsulated concrete slab at least $50 \mathrm{~mm}$ thick poured once the cladding is completed. To the side of the shelter is an uninsulated kitchen extension. The design documentation was updated to reflect the final as-built state; all dimensions and effective opening sizes were verified. Taken as the control for the experiment, no changes from the design approved by UNHCR were made to this shelter.

\subsubsection{Increased ventilation}

Albadra et al. $(2017 ; 2018)$ reported the occupied shelters in the camp (which are identical to the control) developed higher indoor temperatures than that of the external air during the hot season, and occupants cutting additional openings in their shelters to improve ventilation. Therefore, this variant focuses on increased ventilation. A new window facing the original one was included to allow crossventilation (the original design has the main window and door on the same wall). The original vents in the gable ends were sealed and replaced by $100 \mathrm{~mm} \emptyset$ rotating roof cowls and 4 new $100 \mathrm{~mm} \varnothing$ lowlevel vents were installed to promote stack ventilation (Figure 4-c).

\subsubsection{Thermal mass by cavity fill}

The thermal performance of the original thermally lightweight design is bounded by the current outdoor conditions, heating up and cooling down quickly. Given the large daily temperature swing characteristic of this climate (Figure 2), this measure focuses on increasing the thermal mass.

This was achieved by filling the wall cavity ( $60 \mathrm{~mm}$ main walls, $30 \mathrm{~mm}$ gable ends, Figure $4-\mathrm{d}$ ). There is a horizontal steel member that runs around the shelter. It was necessary to cut a horizontal slot $75 \mathrm{~mm}$ below this horizontal member in the internal cladding to allow the sand/gravel mix to be inserted. Cutting the slot necessitated the introduction of a horizontal timber batten $(100 \times 25 \mathrm{~mm})$ to maintain the integrity of the cladding sheets and to prevent bulging. The timber batten was secured using $10 \mathrm{~mm}$ thru-bolts at $600 \mathrm{~mm} \mathrm{c} / \mathrm{c}$. The sand/gravel mix was placed in a labour-intensive process using a small metal chute fabricated form a cladding off cut. Once filled to the top of the sheet, 3 layers of $15 \mathrm{~mm}$ insulation were inserted between the top of the thermal mass infill and the underside of the metal transom. The process was then repeated to just below the eaves' structural member. No thermal mass was added to the gable end above eaves level. Although this prototyped solution does not include sandproof seals, minimal sand loss was reported at the end of the experiment.

\subsubsection{Increased insulation and removal of thermal bridges}

The envelope of this shelter was retrofitted with an additional layer of the same $15 \mathrm{~mm}$ insulation (Figure 4-e). This necessitated removing and re-fixing the wall cladding sheets. The insulation was fixed to the structure using PVC spacers cut from off cuts of $20 \mathrm{~mm} \varnothing$ water pipe to prevent compressing the insulation where it meets the metal frame (not employed in the original T-Shelter design but since adopted as the preferred construction method). The butt joints were staggered and taped. Holes in the IBR panels were sealed with duct tape and gaps were filled with insulation foam.

\subsubsection{Roof shade}

This variant uses a roof shade to minimize solar-related heat gains through the roof (Figure 4-f). In addition, the roof shade overhung the existing walls by an additional $400 \mathrm{~mm}$ to provide shading to the 
south-facing window and to reduce solar gains through the walls. The roof shade was formed from with $150 \mathrm{~mm}$ metal angle $(30 \mathrm{~mm} \times 30 \mathrm{~mm})$ frames at $1000 \mathrm{~mm} \mathrm{c} / \mathrm{c}$, permitting an air path from eaves to ridge, with air exiting via a raised ridge cap (Figure 4-f).

\subsubsection{Thermal mass with internal sandbags}

Following the rationale presented for the cavity fill case, this one has an inner wall cladding of sandbags to benefit from even greater thermal mass (Fosas, Albadra, et al. 2018) (Figure 4-g). The sandbags measured $600 \mathrm{~mm}$ long $\times 250 \mathrm{~mm}$ wide $\times 150 \mathrm{~mm}$ high. In order to save time these were filled off-site and delivered ready for use. The sandbags were bought in long strips, cut down to length and a ribbon was sewn on for tying up the bag. At $600 \mathrm{~mm}$ long, each sandbag weighs $45 \mathrm{~kg}$. The sandbags were compacted using a heavy club hammer, angle straps were fitted to the shelter steel frame and a barbed wire was laid around the perimeter every fifth row. The height of the sandbags was taken to eaves height and up to $1.25 \mathrm{~m}$ on the external side of the kitchen wall.

\subsubsection{XPS insulation and roof shade}

This prototype provides higher insulation levels by replacing the original insulation with $40 \mathrm{~mm}$ extruded polystyrene (XPS, Figure 4-h). The installation process necessitated removal of the outer cladding and the existing insulation sheet. The new interlocking insulation was then fitted, and the wall and roof cladding fixed over. To avoid exacerbating indoor overheating a roof shade was fitted as in the roof shade case but with a $300 \mathrm{~mm}$ gap and no ridge ventilation.

\subsection{Experimental conditions and data collection}

Monitoring started after the completion of the construction work, from the 17th of August until the 7th of October 2018, and access to the fenced compound was controlled by security guards. During the first month every shelter remained closed except for the window of the kitchen extension, which was propped open as well as the four vents of the main space. This allowed a baseline to be obtained for the performance of the shelters. From the 17th of September onwards, a designated person visited the experiment twice a day to operate each shelter. Windows were opened from 09:00 until 21:00 in every shelter except those aimed at increasing thermal mass. For the latter, windows were opened from 21:00 until 09:00 to benefit from the colder night-time temperatures. Doors remained closed outside inspection times.

Indoor conditions were recorded at the centre of each shelter with a temperature and relative humidity logger at 1-hour intervals (iButton DS1923, temperature accuracy $\pm 0.5{ }^{\circ} \mathrm{C}$, relative humidity $\pm 5 \%$, response times under 130 seconds, calibrated by manufacturer in climate chamber). State sensors recorded if the main door and main window were open or closed accordingly to the pre-established ventilation plan. The sensors employed were HOBO UX90-001, which have a pair of magnets to record the times at which the state of the element changes. It must be noted that doors and windows of these shelters are custom-made at the camp from steel angle profiles and have gaps up to $20 \mathrm{~mm}$ whilst shut. This made sensor readings unreliable at times.

In the absence of a local weather station, the conditions were reconstructed combining three sources of information:

1. Onsite sensors: two independent shielded temperature and relative humidity loggers at 1-hour intervals (Tinytag TGP- 4500 , temperature accuracy under $\pm 0.5{ }^{\circ} \mathrm{C}$, relative humidity $\pm 3 \%$, response time up to 25 minutes, IP68, calibrated by manufacturer in climate chamber). 
2. NOAA weather stations (U.S. Department of Commerce 2019): three weather stations $60 \mathrm{~km}$ away triangulate this location (USAF numbers 402 600, 402 700, 403 600). Although complete hourly weather records were not available, those for dry bulb temperature were.

3. MERRA-2 (Gelaro et al. 2017) and CAMS (Schroedter-Homscheidt et al. 2017): MERRA-2 is a reanalysis dataset that contains all the main variables used to reconstruct full weather observations for building simulation except for infrared radiation, cloud cover and the direct/diffuse solar radiation split. This can be combined with the satellite observations from CAMS that provide full solar radiation records and cloud cover during daytime (Fosas, Herrera, et al. 2018).

Given the successful results obtained for weather files based on MERRA-2 and CAMS datasets for this location $^{2}$, a weather file was produced based on them. Cross-comparisons with onsite and NOAA data show that up until the 30th of September the agreement for dry-bulb temperature is about $\pm 1{ }^{\circ} \mathrm{C}$ between the three sources, but MERRA-2 data presents inconsistencies compared to the other two sources from the 30th of September until the 7th of October. Data was taken from the onsite sensors for dry bulb temperature and relative humidity for this period, recalculating the dewpoint for physical consistency of observations.

\subsection{Thermal simulation models}

This study relies on careful management of simulation models to maintain synchronized shared model parameters across shelter variants while controlling those that make each one unique. A custom workflow is implemented to programmatically define models and to simulate, collect and analyse results. Every simulation is based on a template that is later parametrized according to the tasks at hand. The following details the overall modelling approach and consecutive sections describe the input parameters for each model.

The interest of the study is in the as-built thermal performance of the prototypes at design stage. The information regarding geometry, final operation and real weather is considered known for the model. The premise is that both the models and the built prototypes respect the main features of the design intent (e.g. four ventilation vents are in place and opened) but not aspects that are unknown at design stage (e.g. infiltration levels or real weather conditions during the monitoring period). This way, potential performance gaps will be more likely due to the definition of the model and suitability of the simulation approach than to the well-known ones due to weather variability and user behaviour. Therefore, the information for the model template comes primarily from design specifications (UNHCR 2016) and internal communications with UNHCR Jordan (interview with camp authorities about the construction sequence, the materials used and updates to the design information).

The simulation models are created for EnergyPlus v9.0.1 (NREL 2018) and simulated at 10-minute time-steps. The shelter is defined in a single zone that describes the main space. The kitchen unit is considered as self-shading because it is enclosed by a single layer of uninsulated IBR panels with windows propped open for the experiment. The heat balance algorithm chosen is the Conduction Transfer Function and the surface convection model is adapted according to the most suitable one relevant to the conditions developed at each timestep. Heat transfer with the ground is particularly important in these shelters and they are accounted for through the Kiva, a calculation tool that couples the ground and shelter domains using an accurate 2D approximation of the $3 \mathrm{D}$ heat transfers (Kruis \&

\footnotetext{
2 The reasons for the good agreement are that Azraq is in the middle of a geographically homogeneous area that is flat, far from large bodies of water and with a high frequency of clear sky days (Fosas, Herrera, et al. 2018).
} 
Krarti 2017). The influence of surrounding shelter units in this regard is accounted for by setting the far-field width to $1.2 \mathrm{~m}$, half the minimum distance between consecutive shelters. The only thermal mass available to the control shelter is that of the concrete slab.

Natural ventilation is modelled with an airflow network that accounts for stack and wind-driven air exchanges. The casement window is modelled using the real openable area, accounting for frames and anti-burglar bars. This reduced the $0.90 \mathrm{~m}^{2}$ opening in the wall to a free area $0.52 \mathrm{~m}^{2}$ (implemented as a change in window width). The two $152 \mathrm{~mm}$ diameter vents at each gable-end walls are modelled as the hydraulic equivalent rectangle of $139 \mathrm{~mm} \times 278 \mathrm{~mm}$ according to Huebscher (1948). The influence of surrounding shelter units on wind-driven ventilation is accounted for through wind pressure coefficients defined for each element as described next. Infiltration is included in the airflow network as cracks in the building envelope. Given that air permeability of individual elements is unknown, a notional infiltration level is defined for the entire shelter and split between envelope components according to their relative area.

\subsubsection{Control shelter: uncertainties, and blind and calibrated models}

The data available at design stage includes unknowns that require further considerations. These are either missing information from the specification, boundary conditions of the model or aspects judged to be particularly sensitive to the construction process. The parameters are also selected according to the heat transfer mechanism and the perceived potential impact on the model.

1. Thermal properties of elements: The thermal resistance of the $60 \mathrm{~mm}$ air cavity of the walls (30 $\mathrm{mm}$ in the gable-ends) mainly depends on the effective emittance and the convection that develops between the insulation and the IBR panel. Potential values for the resistance are between $0.15 \mathrm{~m}^{2} \cdot \mathrm{K} \cdot \mathrm{W}^{-1}$ and $0.39 \mathrm{~m}^{2} \cdot \mathrm{K} \cdot \mathrm{W}^{-1}$ for cases of these dimensions with low and high effective emittance, respectively (ASHRAE 2017). The conductivity of the foam insulation is not specified, and it is estimated to vary between $0.04 \mathrm{~W} \cdot \mathrm{m}^{-1} \cdot \mathrm{K}^{-1}$ and $0.5 \mathrm{~W} \cdot \mathrm{m}^{-1} \cdot \mathrm{K}^{-1}$. As the insulation layer is simply laid over the metal frame before cladding thermal breaks are likely to occur at structural elements and the foam might be severely compressed where the cladding is bolted to the frame. In addition to changes in conductivity, the average insulation thickness is considered to vary from $5 \mathrm{~mm}$ to $15 \mathrm{~mm}$.

2. Ground thermal properties: The ground temperature underneath the concrete slab affects the internal temperature of the space. Considering that boundary conditions are well-defined through the weather file and that the indoor thermal simulation is coupled to that of the ground, the unknown variable is the effective thermal diffusivity of the ground. This is split between the conductivity and specific heat capacity of the soil for an assumed density of $1300 \mathrm{~kg} \cdot \mathrm{m}^{-3}$. Parameter ranges are described in Table 2, based on soil properties ranging from loose sand to sandstones (CIBSE 2017b; Van Wijk \& De Vries 1963).

3. Ventilation and infiltration: Wind pressure coefficients moderate the effective windspeed for natural ventilation according to the characteristics of the building, its surroundings and the relative angle between every surface and wind direction. Two suitable databases for the characteristics of the shelter and the pattern of surrounding units were identified, that of Swami \& Chandra (1987) and that of Liddament (1996). Similarly, discharge coefficients approximate the relationship between the real and the theoretical mass flow rate through openings. Here, it is assumed to vary between the typical value of 0.60 up to 0.9 (ASHRAE 2017). The infiltration level is particularly difficult to define at design stage because no limit is enforced during construction. Likely bounds are established roughly between 0.5 ach and 2.5 ach according to the two calculation methods, component and whole-building, described by Orme et al. (1998). However, these describe annual averages. The overall leakage flow that causes these air 
changes for this case was found iteratively through simulations with window and vents shut. The total leakage mass flows were $0.05 \mathrm{~kg} \cdot \mathrm{s}^{-1}$ and $0.40 \mathrm{~kg} \cdot \mathrm{s}^{-1}$, respectively (reference air conditions: $20^{\circ} \mathrm{C}, 101,325 \mathrm{~Pa}, 0.014761$ humidity ratio).

Table 2: Uncertain parameters for the control shelter ( $U$ denotes the random distribution: () continuous and \{\} discrete)

\begin{tabular}{|c|c|c|c|c|}
\hline \multirow{2}{*}{ Parameter } & \multirow{2}{*}{ Units } & \multicolumn{2}{|c|}{ Blind models } & \multirow{2}{*}{$\begin{array}{l}\text { Pool for calibrated model } \\
(X\end{array}$} \\
\hline & & Deterministic & Bounded & \\
\hline Resistance cavity & $\mathrm{m}^{2} \cdot \mathrm{K} \cdot \mathrm{W}^{-1}$ & 0.15 & $\{0.15,0.39\}$ & $U(0.15,0.39)$ \\
\hline Insulation conductivity & $\mathrm{W} \cdot \mathrm{m}^{-1} \cdot \mathrm{K}^{-1}$ & 0.04 & $\{0.04,0.5\}$ & $U(0.04,0.5)$ \\
\hline Insulation thickness & $\mathrm{m}$ & 0.015 & $\{0.005,0.015\}$ & $U(0.005,0.015)$ \\
\hline Soil conductivity & $\mathrm{W} \cdot \mathrm{m}^{-1} \cdot \mathrm{K}^{-1}$ & 0.4 & $\{0.4,2.3\}$ & $U(0.4,2.3)$ \\
\hline Soil specific heat capacity & $\mathrm{J} \cdot \mathrm{kg}^{-1} \cdot \mathrm{K}^{-1}$ & 1500 & $\{400,1500\}$ & $U(400,1500)$ \\
\hline Total air leakage $^{a}$ & $\mathrm{~kg} \cdot \mathrm{s}^{-1}$ & 0.05 & $\{0.05,0.4\}$ & $U(0.05,0.4)$ \\
\hline Wind pressure coefficients ${ }^{b}$ & - & Swami & $\{$ Swami, Liddament $\}$ & $U\{$ Swami, Liddament $\}$ \\
\hline Discharge coefficient & - & 0.6 & $\{0.6,0.9\}$ & $U(0.6,0.9)$ \\
\hline
\end{tabular}

${ }^{\text {a }}$ Reference air conditions: $20^{\circ} \mathrm{C}, 101,325 \mathrm{~Pa}, 0.014761$ humidity ratio.

${ }^{\mathrm{b}}$ Implemented as a choice between the two databases for the geometries and angles under consideration.

The blind models for Stage 1 are presented in two variants: deterministic and bounded. In the deterministic variant, it is assumed that the modeller made an informed decision about the values of the uncertain parameters to create a single model. The bounded version, on the other hand, assumes the modeller would perform a naïve parametric analysis with the high and low estimates for each parameter, resulting in 256 different models $\left(2^{8}\right)$.

The calibrated model for Stage 2 represents a different approach to the problem. Here, it is assumed that a prototype of the shelter has been built and monitored. A formal calibration process can take place so that the thermal modeller can learn from the reality behind the model to maximize the agreement between predictions and observations. The process is as follows:

1. Predicted variable: Dry bulb temperature. This is the main driver for thermal comfort and overheating studies, especially in this dry location. For control purposes the calibration also considers relative humidity.

2. Datasets: The observations are split into two datasets. The first $70 \%$ of datapoints, from 17 th August until 21st September, constitutes the calibration dataset to find the best estimates for the uncertain parameters. The remaining $30 \%$ constitute the validation dataset and are used to appraise the goodness of fit of the model using data unseen by the calibration algorithm.

3. Initial samples: The variability of the parameters is assumed to be captured by a random uniform distribution within the bounds or choices identified for the blind models (Table 2). A Latin Hypercube (LH) is created to sample values efficiently. In particular, a maximum projection design to build the $\mathrm{LH}$ is used because it guarantees adequate space-filling properties across all its subspaces (Joseph et al. 2015; Ba \& Joseph 2018). This is desirable since it is unknown beforehand if every parameter is influential in the calibration. A pool with a number of samples 10 times the number of parameters involved is built using this method to feed the calibration algorithm.

4. Calibration: The model is calibrated through Calibro, a program by Monari \& Strachan (2017). Their algorithm is agnostic to the building simulation engine and performs principal component analysis, sensitivity analysis and builds a black-box model that allows finding which parameters from those in Table 2 are influential and what their best estimates are. 
5. Calibrated model: The calibrated model is created with the best estimates of influential parameters identified in the previous step.

6. Validation: The validation dataset is used to judge whether the prediction performance of the calibrated model outperforms those of the blind models.

\subsubsection{Design alternatives}

The six design alternatives share the same template and modelling techniques as those of the control shelter except for the reported changes (Table 3) and geometric and shading conditions (Figure 5) according to their location in the compound (Figure 3). Two types of models are built per design alternative, one based on the blind models (Stage 1) and another based on the best parameter estimates of the calibration (Stage 2).

Table 3: Model differences between design alternatives and control shelter

\begin{tabular}{ll}
\hline Model & Differences \\
\hline Increased ventilation & $\begin{array}{l}\text { A new window opposite the current one is added to the model with the same } \\
\text { characteristics. Four new vents with the same hydraulic characteristics are } \\
\text { added at low level. Given the limitations of the airflow network to model } \\
\text { rotating roof cowls these are modelled like the original vents in the control } \\
\text { shelter since the main expected driver for background ventilation is } \\
\text { infiltration and the stack effect. }\end{array}$ \\
\hline $\begin{array}{l}\text { Thermal mass by } \\
\text { cavity fill }\end{array}$ & $\begin{array}{l}\text { The } 60 \mathrm{~mm} \text { cavity in the walls }(30 \mathrm{~mm} \mathrm{in} \mathrm{the} \mathrm{gable} \mathrm{ends)} \mathrm{is} \mathrm{filled} \mathrm{up} \mathrm{to} \mathrm{eaves} \\
\left.\text { level with dry sand (conductivity } 0.6 \mathrm{~W} \cdot \mathrm{m}^{-1} \cdot \mathrm{K}^{-1}\right) \text {. The window opens from } \\
\text { 21:00 until 09:00 from the } 17 \text { th of September onwards. }\end{array}$ \\
\hline Increased insulation & Insulation thickness is doubled and includes the doors. \\
\hline Roof shade & $\begin{array}{l}\text { A simple roof shade is implemented by adding external shading surfaces. No } \\
\text { other adjustments are made to the airflow in the baffle zone nor to its heat } \\
\text { balance model. }\end{array}$ \\
\hline $\begin{array}{l}\text { Thermal mass with } \\
\text { internal sandbags }\end{array}$ & $\begin{array}{l}\text { An internal layer of } 250 \mathrm{~mm} \text { sandbags with the same characteristics as the } \\
\text { cavity fill is added up to eaves level of every wall. The kitchen wall has } \\
\text { sandbags on the external side and up to } 1.25 \text { m. The new roof cowls are } \\
\text { implemented like in the 'increased ventilation' case. The window opens from }\end{array}$ \\
& $21: 00$ until $09: 00$ from the 17 th of September onwards. \\
\hline $\begin{array}{l}\text { XPS insulation and } \\
\text { roof shade }\end{array}$ & $\begin{array}{l}\text { The structure is covered with } 40 \mathrm{~mm} \text { XPS insulation panels (conductivity } \\
0.035 \mathrm{~W} \cdot \mathrm{m}^{-1} \cdot \mathrm{K}^{-1} \text { ) instead of the original foam insulation. A roof shade is } \\
\text { implemented in the same way as the previous case. }\end{array}$ \\
\hline
\end{tabular}

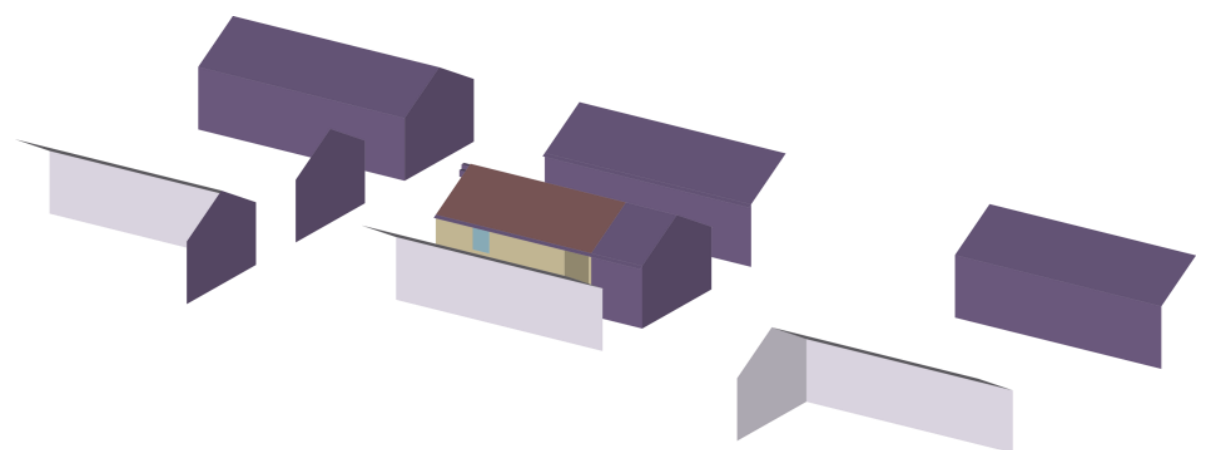

Figure 5: Simulation model template overview (bounding box for thermal zone: $6.1 \mathrm{~m} \times 4.1 \mathrm{~m} \times 3.3 \mathrm{~m}$; $28^{\circ}$ double-pitched roof; North and active shading surfaces vary according to the case as per Figure 3; optional roof shades not displayed) 


\subsubsection{Prototyping in a country with a different climate}

Similar to the research compound established in Azraq, the HHftD project has a local facility in South West England (UK, warm temperate, fully humid, warm summer climate (Cfb) according to the Köppen-Geiger climate classification (Kottek et al. 2006)). Lacking a prototype of the Azraq transitional shelter in the UK, the inter-agreement between the performance of simulation models presented above in these two climates is measured. This option is only reliable if the results obtained for the simulation models indicate good agreement against monitored data. The temperate climate of the UK is considered as an example of a very different type of weather to the hot arid one of Azraq in Jordan. If the overall inter-agreement between rankings is indeed maintained in this situation, it could be speculated that it could be also the case for those climates that fall within these two.

\subsection{Analysis}

Unless there is an exact match between the simulated thermal performance of the prototype and the experimental data, a judgement needs to be made on the adequacy of the results. Yet, there is no agreement as to what constitutes a good-enough simulation model. Three approaches are here considered: qualitative, quantitative and a domain-specific evaluation. As the focus is on the improvement of indoor thermal conditions, only dry bulb temperature is reported as the main proxy to evaluate thermal indoor environments in this hot dry climate.

The qualitative approach is the visual agreement between experimental observations and simulation in the time series. For example, simulations need to replicate not only the magnitude of the variable (e.g. amplitude and average) but also its hourly trends (e.g. frequency and phase).

The quantitative approach is based on the criteria defined by ASHRAE (2014). In the context of energy, the guideline considers whether a model is calibrated by appraising numerically the goodness of fit between simulated and monitored data. Here, these criteria are applied to dry bulb air temperature. They are based on a pair of indicators for the variable at hand, one for the overall mean error and another for the goodness of fit at timestep level. These are the Mean Bias Error (MBE, Equation 1) and the Coefficient of Variation of the Root Mean Squared Error (CV(RMSE), Equation 2), respectively,

$$
\begin{array}{rlr}
M B E & =\frac{\sum_{i=1}^{N} T_{o b s, i}-T_{, i}}{\sum_{i=1}^{N} T_{o b s, i}} & \text { Equation 1 } \\
C V(R M S E) & =\frac{\sqrt{\frac{1}{N} \sum_{i=1}^{N}\left(T_{o b s, i}-T_{, i}\right)^{2}}}{\overline{T_{o b s}}} & \text { Equation 2 }
\end{array}
$$

where $T_{o b s, i}$ denotes the observed temperature at hour $i, T_{, i}$ the simulated one, $N$ the total number of timesteps and $\overline{T_{o b s}}$ the mean observed temperature. Notice that both indicators are scalar quantities that take observations as the reference, with 0 indicating perfect agreement. ASHRAE criteria considers a model is calibrated if the MBE is within $\pm 10 \%$ and the CV(RMSE) is within $\pm 30 \%$. For this experiment, the CV(RMSE) can only be positive since observed averages are positive.

The domain-specific approach is derived from the rationale behind thermal discomfort studies to appraise the frequency and the severity of the deviation from comfortable temperatures. Here, the focus is on air temperature differences binned at $1{ }^{\circ} \mathrm{C}$ as the fundamental metric upon which proposed overheating criteria rest on (CIBSE 2013; 2017b; 2017a). 
Lastly, there is a need to evaluate if prototyping shelters in a different climate to that where they are going to be used at provide reliable insights of performance. Since the thermal performance is determined by the climate, the rankings of the MBE and CV(RMSE) are compared because these metrics normalize the response against a selected baseline. The rankings obtained for each metric and climate can then be analysed using non-parametric rank correlation analyses after Kendall (Kendall 1938; Knight 1966) and Spearman (Spearman 1904; Kokoska \& Zwillinger 2000). These statistics characterize correlation with a coefficient $r$ where $r \in[-1,+1]$. A value of 0 indicates no correlation, +1 positive correlation and -1 negative correlation. The null hypothesis of these tests is that there is no difference between the two rankings $(r=0)$.

These analyses are carried out in Python (Python Software Foundation 2019), its scientific ecosystem (Perez \& Granger 2007; Kluyver et al. 2016; van der Walt et al. 2011; McKinney 2010; Hunter 2007; Kibirige 2019; Waskom 2018; Roubeyrie \& Celles 2018; VanderPlas et al. 2018; Pedregosa et al. 2011; Jones et al. 2001) and R (R Core Team 2019).

\section{Results}

\subsection{Blind model}

The focus is first on the extent to which blind models replicate the performance of the monitored shelter prototype (Figure 6). Overall, blind models can replicate the trends of the monitored data in terms of averages, frequency and phase, following closely values recorded outdoors (Figure 6-a). The amplitude depicted by the daily maximum and minimum temperatures show deviations between $+5{ }^{\circ} \mathrm{C}$ and $-3{ }^{\circ} \mathrm{C}$ with regards to the monitored ranges, respectively. These deviations reach their maximum values in the period where openings other than vents remained closed, between the beginning of the experiment (17th of August) and day when the natural ventilation control strategy changed (17th of September). Afterwards, in the period when the window was opened from 09:00 to 21:00, disagreement in simulated maximum and minimum daily temperatures remained under $\pm 3{ }^{\circ} \mathrm{C}$. The amplitude of the sample case (deterministic simulation) is below the average of all blind models, which results in a better agreement to experimental temperatures.

The numerical evaluation of the goodness of fit indicates that every blind model satisfies the criteria of the ASHRAE guideline (Figure 6-b). The overall mean agreement reported by the MBE is in the $\pm 6 \%$ interval, within the pre-established limits of $\pm 10 \%$ and with some instances having no bias at all. Values of $\mathrm{CV}$ (RMSE) are also under the $30 \%$ limit, with minimum values under $4 \%$. The deterministic case shows a higher bias than most models while it outperforms them when considering hourly deviations from experimental data.

The histogram quantifies how often the mismatch between every blind simulation to the monitored data falls in the predefined bins, neglecting agreements within the $\pm 0.5{ }^{\circ} \mathrm{C}$ sensor accuracy (Figure 6-c). The overall asymmetry between positive and negative intervals indicate blind simulations tend to be warmer than the monitored data, consistent with the average negative results for MBE. The best-case scenario is outside observed ranges $57 \%$ of the time and the worst $88 \%$, with most differences taking place in the bins between $\pm 1{ }^{\circ} \mathrm{C}$. If mismatches in that interval are neglected, numbers fall to $13 \%$ and $43 \%$, respectively. Differences can be greater than $+4{ }^{\circ} \mathrm{C}$ up to $15 \%$ of the time. 


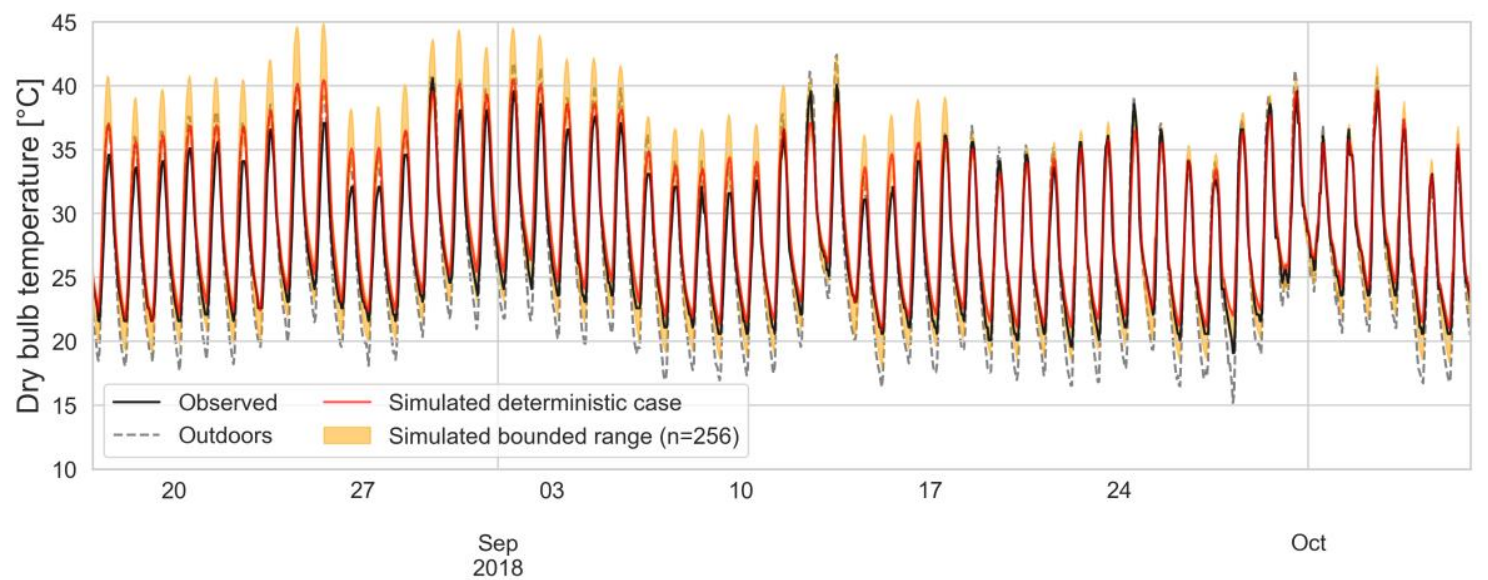

a) Simulation results versus monitored data

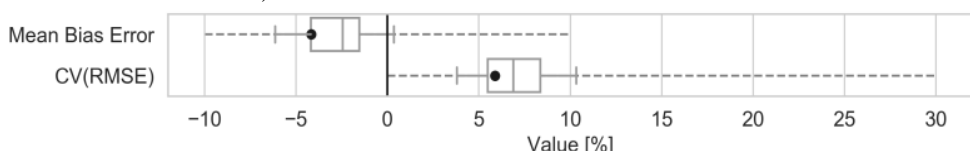

b) Goodness of fit according to ASHRAE Guideline 14 (2014) (whiskers span the minimum and maximum value; dot represents the deterministic case; dashed lines represent acceptability range)

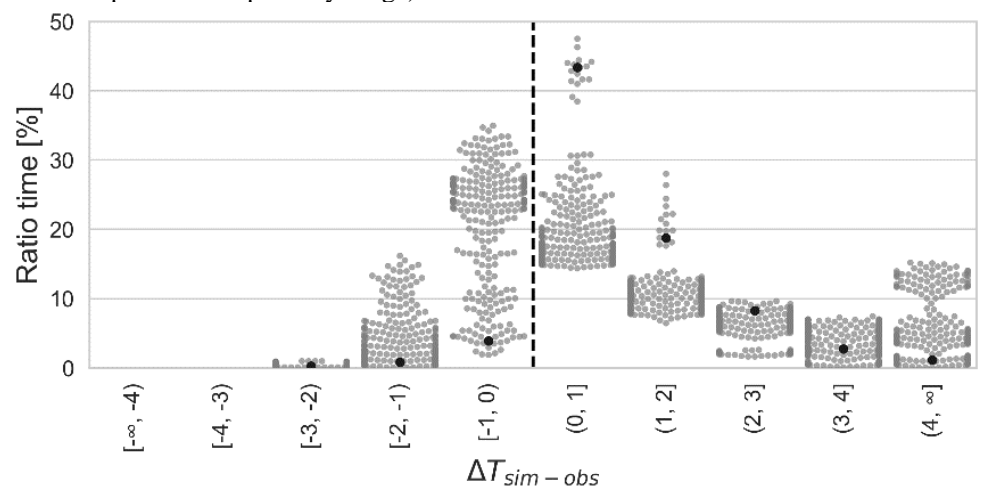

c) Histogram of $\Delta T_{-o b s}$ (grey represents all cases in the training pool; black represents the deterministic case; dashed line indicates 0 ; $\left.\Delta T_{-o b s} \in[-2.93,+8.93]\right)$

Figure 6: Results Stage 1: Blind models 


\subsection{Calibrated model}

The LHS-based simulations capture the variability in internal temperatures to a resolution better than $1{ }^{\circ} \mathrm{C}$ using only $30 \%$ of the number of simulations of the parametric approach (Figure 7 -a). The calibration process selected six parameters out of the eight as relevant to improve the goodness of fit to the observations, with total air leakage as the most influential parameter (Table 4). The calibrated simulation outperforms the random ones by the LHS in both the training and validation periods (from the 22nd of September onwards, $30 \%$ of the data), showing a performance that is not necessarily bounded by the ranges obtained by the LHS. The numerical evaluation shows a similar quantification to the one obtained previously, albeit with a $2 \%$ narrower range (Figure 7-b). Here, the calibration process optimizes both the MBE and the CV(RMSE) which score values under $1 \%$ and $4 \%$ for both indicators $^{3}$, respectively. This means that the calibrated case is, on average, within $0.4{ }^{\circ} \mathrm{C}$ of the observed data. The overall effect of the calibration is to centre the distribution of temperature differences around $0{ }^{\circ} \mathrm{C}$ while decreasing deviations greater than $3{ }^{\circ} \mathrm{C}$ at the same time (Figure 7-c).

Table 4: Results Stage 2: Summary of calibrated parameters ( $U$ denotes the random distribution: () continuous and \{\} discrete; - indicates a non-influential parameter in the calibration)

\begin{tabular}{|c|c|c|c|c|}
\hline Parameter & Units & Estimated uncertainty & $\begin{array}{l}\text { Sensitivity } \\
\text { ranking }\end{array}$ & Parameter estimates \\
\hline Total air leakage $^{a}$ & $\mathrm{~kg} \cdot \mathrm{s}^{-1}$ & $U(0.05,0.4)$ & 1 & 0.3666 \\
\hline Insulation conductivity & $\mathrm{W} \cdot \mathrm{m}^{-1} \cdot \mathrm{K}^{-1}$ & $U(0.04,0.5)$ & 2 & 0.0432 \\
\hline Soil conductivity & $\mathrm{W} \cdot \mathrm{m}^{-1} \cdot \mathrm{K}^{-1}$ & $U(0.4,2.3)$ & 3 & 2.1512 \\
\hline Resistance cavity & $\mathrm{m}^{2} \cdot \mathrm{K} \cdot \mathrm{W}^{-1}$ & $U(0.15,0.39)$ & 4 & 0.3628 \\
\hline Insulation thickness & $\mathrm{m}$ & $U(0.005,0.015)$ & 4 & - \\
\hline $\begin{array}{l}\text { Wind pressure coefficients } \\
\mathrm{b}\end{array}$ & - & $U\{$ Swami, Liddament $\}$ & 4 & - \\
\hline Soil specific heat capacity & $\mathrm{J} \cdot \mathrm{kg}^{-1} \cdot \mathrm{K}^{-1}$ & $U(400,1500)$ & 5 & 1480.52 \\
\hline Discharge coefficient & - & $U(0.6,0.9)$ & 6 & 0.6303 \\
\hline
\end{tabular}

${ }^{a}$ Reference air conditions: $20^{\circ} \mathrm{C}, 101,325 \mathrm{~Pa}, 0.014761$ humidity ratio.

${ }^{\mathrm{b}}$ Implemented as a choice between the two databases for the geometries and angles under consideration.

\footnotetext{
${ }^{3}$ These values are representative of the performance of the calibrated simulation for both the validation and the complete period of the experiment. The shelter remained completely closed except for the vents until the 17th of September, causing a wider variability in the performance of the simulations. This causes metrics for the validation period to outperform those of the training — and hence those of the complete period as well. Here, it was opted to report the maximum absolute values.
} 


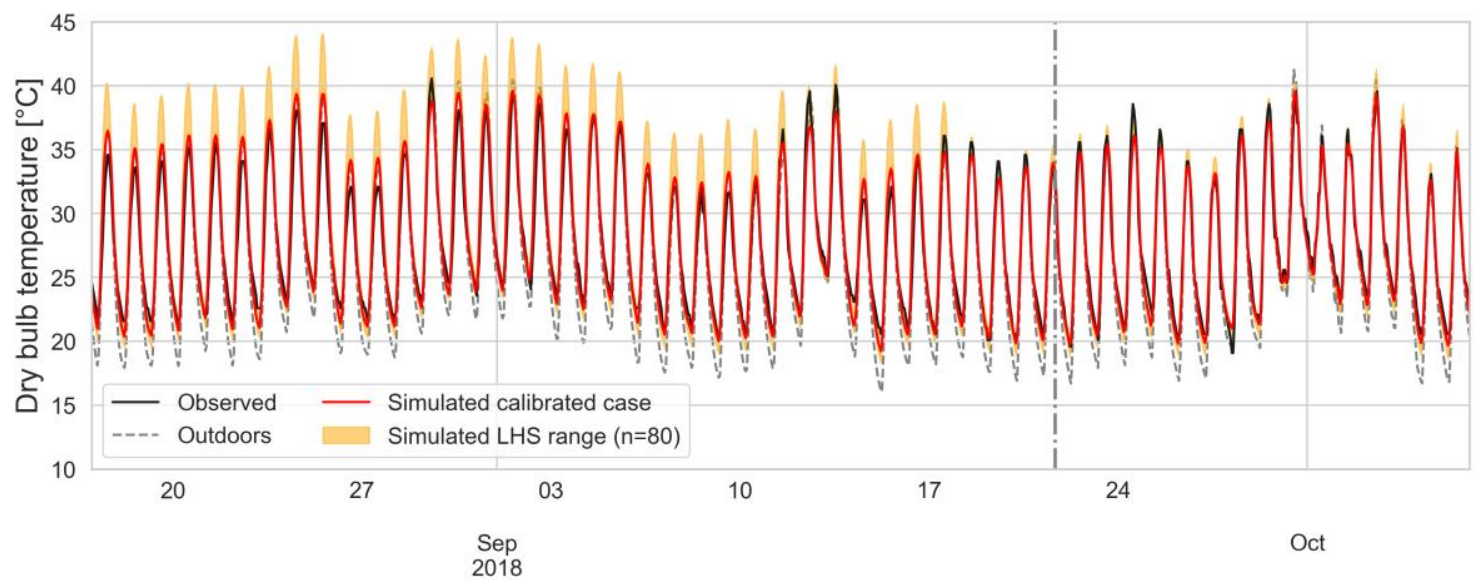

a) Simulation results versus monitored data (dashed line separates training data for the calibration on the left to the one for validation on the right)

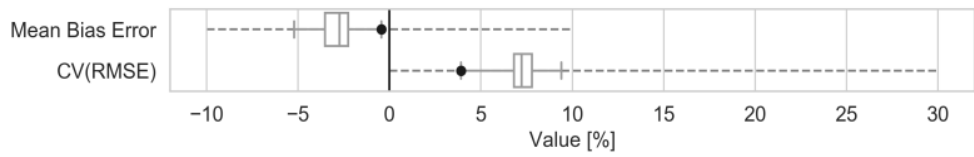

b) Goodness of fit according to ASHRAE Guideline 14 (2014) (whiskers span the minimum and maximum value; dot represents the calibrated case; dashed lines represent acceptability range)

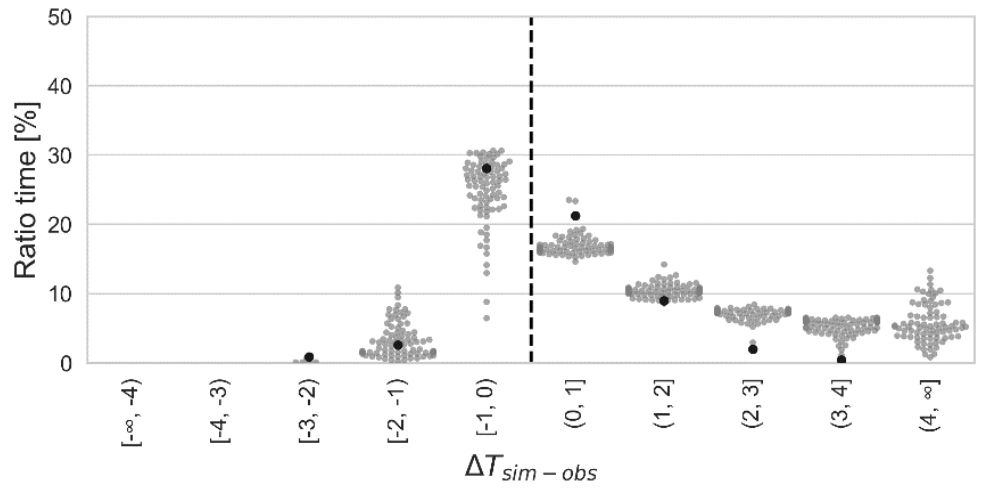

c) Histogram of $\Delta T_{-o b s}$ (grey represents all cases in the training pool; black represents the calibrated case; dashed line indicates 0 ; $\left.\Delta T_{-o b s} \in[-2.59,+8.13]\right)$

Figure 7: Results Stage 2: Calibrated models 


\subsection{Design alternatives}

The overview of the average temperatures developed in shelter alternatives show their effectiveness in mitigating overheating (Figure 8). In general, simulations capture the observed results in every case except those with increased thermal mass. In the latter, experimental results show lower temperatures than in any of the simulations, and markedly so in the case of the sandbags variant. Considering that the measurement error for air temperature is $\pm 0.5^{\circ} \mathrm{C}$, the cases that significantly reduce peak temperatures are: increased thermal mass with sandbags $\left(3.98^{\circ} \mathrm{C}\right)$, increased thermal mass by cavity fill $\left(2.27^{\circ} \mathrm{C}\right)$, roof shade $\left(1.34{ }^{\circ} \mathrm{C}\right)$, increased insulation $\left(1.23^{\circ} \mathrm{C}\right)$ and XPS insulation with roof shade $\left(0.95^{\circ} \mathrm{C}\right)$.

The results for the goodness of fit are grouped into two according to their base model (Figure 9). The first group displays the performance of simulations based on the blind models for the control case, whereas the second is based on the best parameter estimates obtained through the calibration process of that same case. Every case displays an improved range for goodness of fit metrics when simulations are based on calibrated models. The average MBE across all the blind simulations for each prototype decrease from $2.7 \%$ to $1.7 \%$, and $\mathrm{CV}$ (RMSE) are reduced from $6.7 \%$ to $4.8 \%$.

The general improvements in the goodness of fit are further quantified in the classification of temperature differences (Figure 10). The effect of the calibration in all circumstances is to centre the distribution of values next to $0{ }^{\circ} \mathrm{C}$ differences and penalize large deviations.

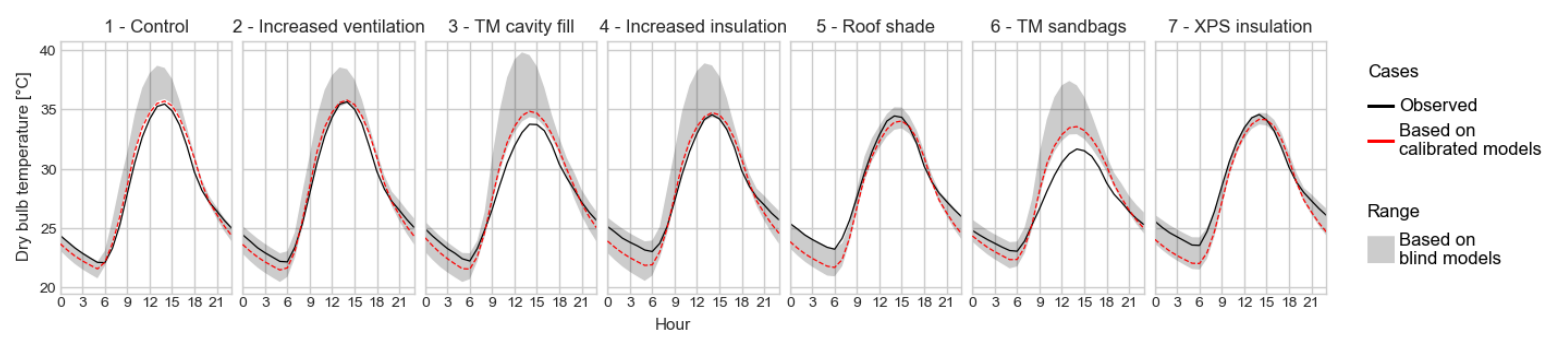

Figure 8: Results Stage 3: Design alternatives - Overview of temperatures (hourly averages)

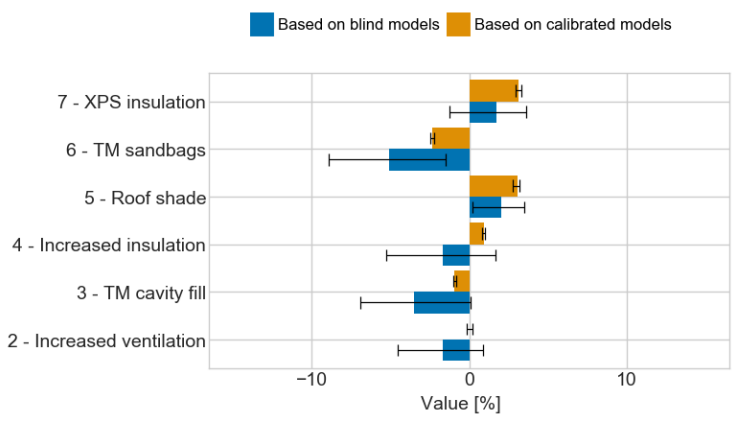

a) Mean Bias Error (acceptability criteria within $\pm 10 \%$ )

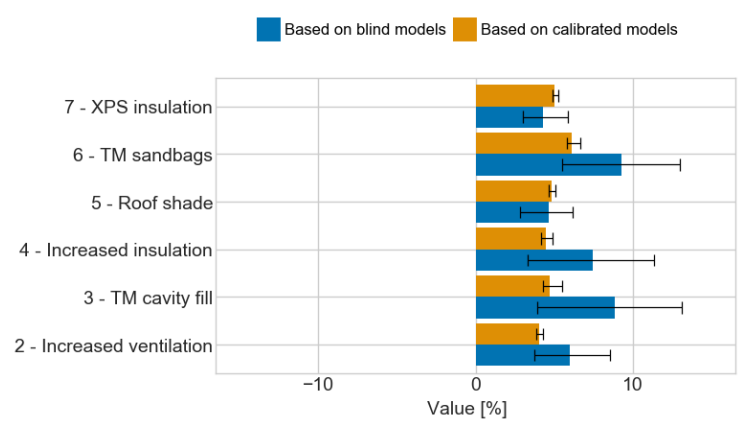

b) $\mathrm{CV}$ (RMSE) (acceptability criteria within $\pm 30 \%$ )

Figure 9: Results Stage 3: Design alternatives - Goodness of fit (acceptability criteria by ASHRAE Guideline 14 (2014); whiskers span the minimum and maximum value) 


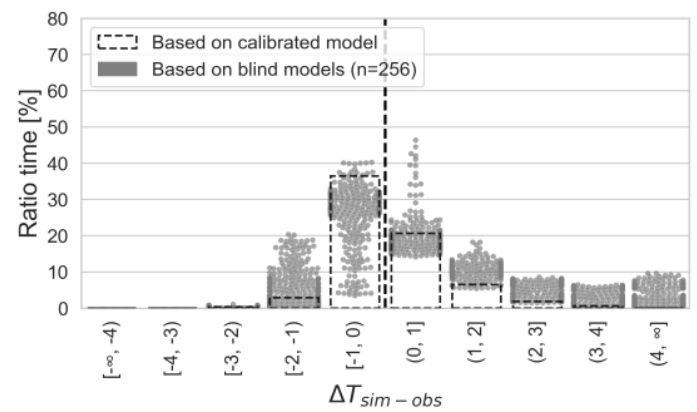

a) Increased ventilation $\left(\Delta T_{-o b s} \in[-2.75,+8.31]\right)$

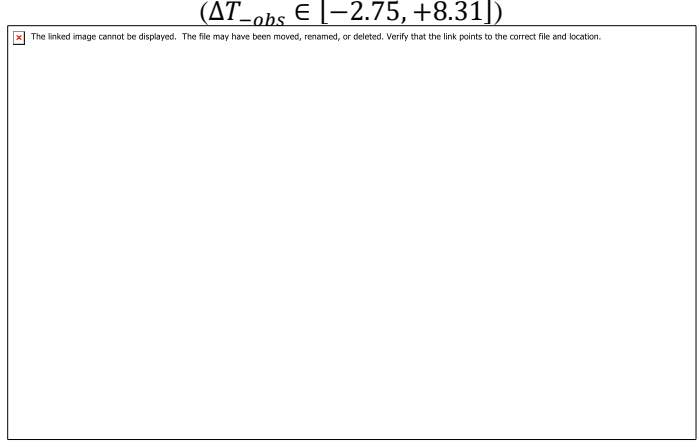

c) Increased insulation $\left(\Delta T_{-o b s} \in[-3.55,+10.42]\right)$

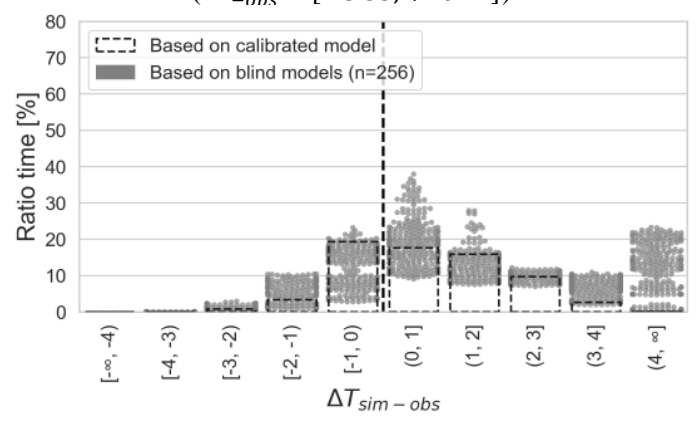

e) Thermal mass with internal sandbags $\left(\Delta T_{-o b s} \in[-3.07,+9.30]\right)$

Figure 10: Results Stage 3: Design alternatives - Histograms of $\Delta T_{-o b s}$

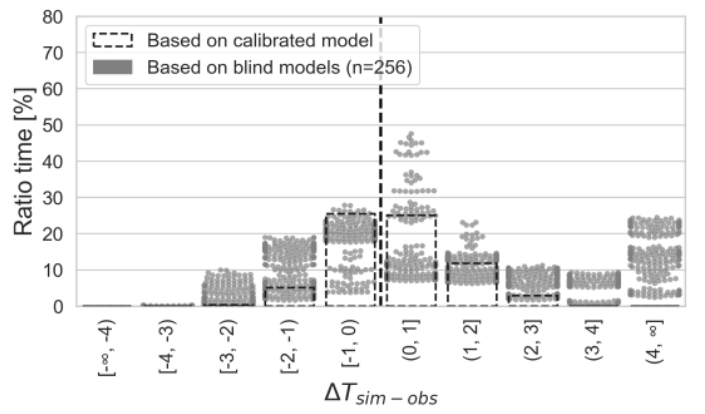

b) Thermal mass by cavity fill $\left(\Delta T_{-o b s} \in[-3.14,+9.72]\right)$

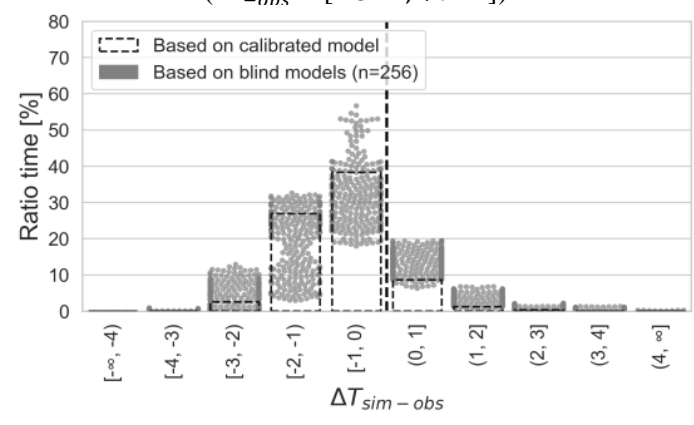

d) Roof shade

$\left(\Delta T_{-o b s} \in[-3.72,+4.13]\right)$

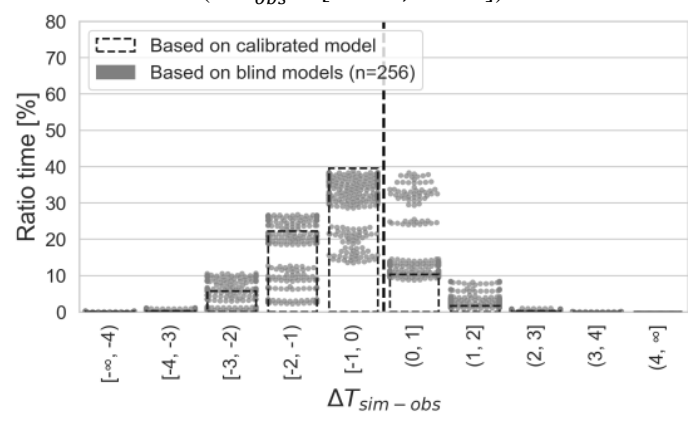

f) XPS insulation and roof shade

$\left(\Delta T_{-o b s} \in[-4.69,+3.09]\right)$

\subsection{Prototyping shelters in countries with different climates}

There is a positive rank correlation of goodness of fit metrics between models simulated in the intended climate of use (Azraq, Jordan) and the hypothesised location for off-site prototyping (South West England, UK; Figure 11). There is a strong correlation for MBE under Kendall's rank correlation coefficient $\left(r_{\tau}=0.79\right.$, p-value $\left.\ll 10^{-5}\right)$ and Spearman's $\left(r_{s}=0.93\right.$, p-value $\left.\ll 10^{-5}\right)$, similarly to those for the CV(RMSE) $\left(r_{\tau}=0.81\right.$, p-value $\ll 10^{-5} ; r_{s}=0.94$, p-value $\left.\ll 10^{-5}\right)$. Therefore, these results suggest rejecting the null hypothesis of no correlation in every case and rank correlation metric. 


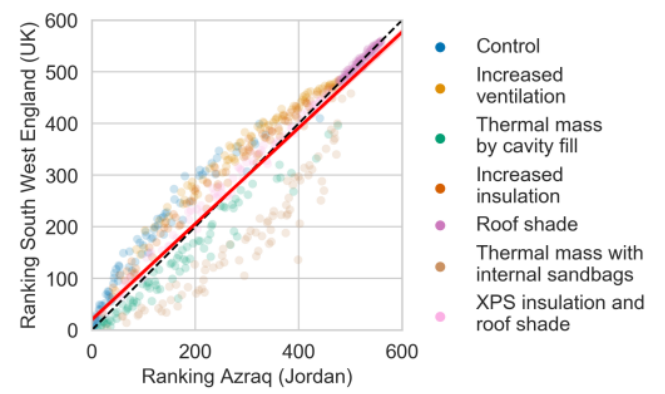

a) Mean Bias Error

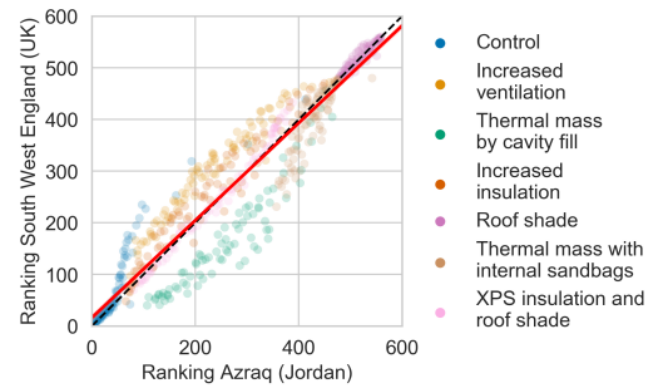

b) CV(RMSE)

Figure 11: Results Stage 4 - Ranking of goodness-of-fit metrics of models in different locations by shelter prototype (sample size: 560 cases; dashed line: reference for perfect agreement, continuous line: fitted agreement)

\section{Discussion}

Results show that building thermal simulation can predict indoor temperatures in the shelters if modelling uncertainties are accounted for. This is illustrated by the difference between the deterministic and bounded (i.e. including uncertainties) approaches when modelling the control shelter. However, the merits of the simulation cannot be determined from the performance obtained when using purge ventilation because, in such circumstances, the indoor temperatures of these single-zone light-weight shelters rapidly approach that of the external environment (Figure 6-a). This would only test the ability of the weather file to replicate experimental conditions, which is what is observed in the period between the 17th of September until the 7th of October for the control case. On the contrary, the advantages of modelling are illustrated in the previous period, when shelters remained closed. Educated guesses on which parameters should be considered unknown and the likely bounds of their values proves key in capturing the real behaviour of the shelter (Figure 7-a). This is because, although eight parameters represent but a small fraction of those defined in a high-fidelity building simulation model, the responses obtained are bounded to a $5{ }^{\circ} \mathrm{C}$ band. The quantification of the goodness of fit through the MBE and the CV(RMSE) indicators suggest an overall good agreement, which corroborates that simulations capture the dynamics of the physics involved.

Whether such agreements are meaningful for studies on overheating needs further discussion. In fact, the goodness of fit evaluation contrasts with the differences between modelled and monitored indoor temperatures depicted in the histogram. As a reference, note that the failure standard in current overheating criteria starts at excursions of just $1{ }^{\circ} \mathrm{C}$ over acceptable temperatures for either $1 \%$ annual occupied hours or $3 \%$ of hours during the hot season; or a $4{ }^{\circ} \mathrm{C}$ excursion at any time (CIBSE 2013; $2017 \mathrm{a} ; 2017 \mathrm{~b}$ ). Indoor temperatures in the blind models exceed observed temperatures by more than $1{ }^{\circ} \mathrm{C}$ between $30 \%$ and $80 \%$ and $4{ }^{\circ} \mathrm{C}$ differences between $0 \%$ and $15 \%$ during the 50-day experiment, rendering overheating predictions useless for compliance purposes. The only application of these simulations for overheating studies is a posteriori, once it is known that no overheating will take place in reality if none is shown in the simulation. Desirable scores in goodness of fit metrics are a necessary but not sufficient condition.

As a result, model calibration is key to faithfully portraying the thermal performance of a shelter. The process rigorously characterizes the sensitivity of the model to input parameters and, while the MBE and the CV(RMSE) metrics show a modest improvement in prediction performance, the histogram captures clear qualitative improvements over the blind models. Absolute temperature differences greater than $3{ }^{\circ} \mathrm{C}$ are eradicated and remaining differences greater than $1{ }^{\circ} \mathrm{C}$ are reduced from $80 \%$ to approximately $15 \%$. Yet, these improvements might be still insufficient to reliably assess compliance with overheating criteria. 
The best parameter estimates further support the case for prototyping and calibrating simulations (Table 4). The reason for this is exemplified in the sensitivity analysis which suggests that total air leakage is the most important parameter, as it is one that can only be known after building a shelter. Indeed, the fitted value is close to the pre-established upper bound, whereas conventional wisdom might have suggested the middle of the interval. Next in rank are the conductivity of the shelter envelope, namely insulation, air cavity and soil. The results for wind pressure and discharge coefficients highlight the importance of considering obstructions in natural ventilation, even in this low-rise scenario, because the optimal discharge coefficient is still close to the lower bound of 0.60 .

The role of all these values are of limited practical importance for this case study when appraising overheating in free-running conditions because this only demonstrates that unoccupied shelters properly operated will not exacerbate indoor temperatures in the hot season. Yet, they still give useful parameter estimates to predict thermal conditions in the cold season, an equally important time of the year in this climate. For example, infiltration levels, insulation and soil conductivities are key parameters for the heat loss of the shelter, and directly proportional to the heating energy demand in the cold season.

A more critical finding is the identification of the key problem in the as-built performance of the control prototype: the need to consider designs that actively mitigate overheating. This directly addresses what problem needs solving. The fact that this is a conclusion attainable even through the relatively coarse process of blind simulations attests to both the scale of the problem and the utility of modelling. The extent to which proposals are of practical value is yet to be determined through an experiment that accounts for internal heat gains, an aspect that could not be included given the lack of power supply at the time the study was conducted. Given the dynamics of free running buildings, it could be hypothesised that monitoring these single-zone buildings is only required for a short period of time if the different heat transfer mechanisms are adequately stressed to facilitate the measurement of the building properties involved. For example, envelope characteristics are best established with openings shut so that conduction and radiation drive the heat exchange, which facilitates measuring airtightness as well. Opening the envelope facilitates measurements of natural ventilation or thermal inertia could be characterized by intermittent internal heat gains.

Overall, simulation models for design alternatives do benefit from the calibration of the control. The histogram shows that every case benefitted from calibrated estimates in the same way as the control shelter. Only the cases with increased thermal mass do not completely capture the variability in the response. Here, the minimum peak temperature in the simulation is still above that observed by up to $1.25{ }^{\circ} \mathrm{C}$. This is attributable to the assumed thermal conductivity of the sand, which is known to vary ten-fold according to water content and voids ratio (Haigh 2012). Further consideration of uncertainties in new parameters of design alternatives would have captured the observed range completely ${ }^{4}$. Nevertheless, the effectiveness of thermal mass in reducing peak temperatures is clearly quantified. These findings are noteworthy considering that (1) calibrated estimates are fitted for a single shelter prototype; (2) no assumptions were made on the distribution of these parameters when applied to different cases; (3) the process was seamlessly applied to design alternatives whose strategies are closer to those of the control shelter (increased ventilation, increased insulation, roof shade) and those that

\footnotetext{
${ }^{4}$ It must also be noted that, in this experiment, design alternatives are implemented retrofitting existing shelters. Although some strategies would have delivered increased airtightness (increased insulation, increased thermal mass by cavity fill), having to disassemble the envelope and re-drill the IBR panels to the structure likely had the opposite effect.
} 
modify them substantially (increased thermal mass, XPS insulation). No diminishing advantages of calibrating the base model are observed in this study.

Lastly, results also support the possibility of prototyping shelter solution off-site in other countries, even if these have different climates. The correlation coefficients indicate that changes in performance in one climate can be extrapolated to the other, which justifies the possibility of developing shelter prototypes remotely to the crisis. This could be particularly useful to aid agencies with established headquarters in locations far from the areas in need, for example, UNHCR in Geneva. However, it must be noted that the rank correlation, although statistically significant, is not perfect. This is to be expected as different design alternatives exercise different heat and mass transfer mechanisms, all of which are tightly coupled to the climate in these shelters. For example, the categories furthest from the perfect agreement in Figure 11 are those dealing with increased ventilation and thermal mass. Since the operation of the shelters in both climates is identical in the simulation, this can be attributed to changes in the temporal signature of external air temperatures and wind speeds. Considering that the warm temperature climate of the UK is very different to the hot arid one of Azraq, it is expected that cases in-between display similar, if not better, correlation coefficients.

\section{Conclusions}

The thermal performance of shelters is an aspect largely overlooked in their design process, yet emerging evidence indicates that only security and safety are more important to surveyed shelter dwellers (Albadra et al. 2017). This paper investigated if the thermal performance of transitional shelters can be studied and improved through high-fidelity building simulation or if building and monitoring shelter prototypes, either on-site or off-site, is to be preferred. Seven shelter were built in the Azraq refugee camp (Jordan) and their indoor thermal conditions monitored during 50 days in the hot season to compare them to predictions by building simulations. These shelters represent the original design implemented (treated as a prototype) in the 8,952 shelters in the camp and six employing passive overheating countermeasures.

The results indicate that:

1. Blind thermal models - those based on design specifications and educated estimates - can only be used to characterize the sensitivity to model parameters and to identify performance limits of design strategies against overheating.

2. Calibrated models could not still be used to reliably predict compliance with recommended overheating criteria either because of the strict limits to overheating duration, but the improvements in indoor air temperature predictions allow a sufficient characterization of the thermal performance.

3. The advantages of calibrating the model are still maintained when comparing the predictions of different design alternatives based on both blind and calibrated models to experimental results.

4. Shelters could be prototyped off-site, even in countries with different climates, since overall relative changes in performance remained constant.

It is therefore concluded that building simulation should be adopted as part of the design process of transitional shelters to give insights of future performance of drafted solutions. Blind simulations can be used to have gross estimates of performance and identify likely limits, but this predicates on expert judgement to identify appropriate value ranges for key model parameters. Results strongly support the case for model calibration to maximize the usefulness of the simulation. Considering the shelter 
provision process, the study advocates for routinely building and monitoring a transitional shelter prototype during the emergency stage of a crisis. The information collected can then be used to calibrate a model and increase the confidence in predictions not only for the prototype design but also for design variants.

\section{Acknowledgements}

This research was funded by the EPSRC [grant number EP/P029175/1] and was conducted thanks to the collaboration of the UNHCR and the NRC. Authors particularly thank Vincent Dupin and Alaa Amoush from UNHCR for facilitating the resources to build and conduct the experiment and the support of Omar Bani-Ahmad Otum from Princess Sumaya University for Technology. Authors also express their gratitude to all those involved in its construction and setup, specially to Ayoub Ibrahim Al Samawi, Luay Ali Albrek and Natalia Paszkiewicz. Daniel Fosas appreciates the support of the EPSRC 'dCarb' CDT [grant number EP/L016869/1] and the 'laCaixa' Foundation. This research was possible thanks to cited open source software and the outstanding communities behind them.

\section{Data Access Statement}

Data presented in this study are openly available at https://doi.org/10.15125/BATH-00668 (Fosas et al. 2019).

\section{Disclosure statement}

No potential conflict of interest was reported by the authors.

\section{References}

Albadra, D. et al., 2017. Thermal comfort in desert refugee camps: An interdisciplinary approach. Building and Environment, 124, pp.460-477.

Albadra, D., Coley, D. \& Hart, J., 2018. Toward healthy housing for the displaced. The Journal of Architecture, 23(1), pp.115-136.

American Society of Heating Refrigerating and Air-Conditioning, 2017. 2017 ASHRAE handbook: Fundamentals (SI), Atlanta: American Society of Heating Refrigerating and Air-Conditioning.

American Society of Heating Refrigerating and Air-Conditioning Engineers, 2014. Guideline 14-2014, Measurement of Energy and Demand Savings, Atlanta: American Society of Heating, Refrigerating and Air-Conditioning Engineers.

Ba, S. \& Joseph, V.R., 2018. MaxPro: Maximum Projection Designs. [Online]. Available from: https://CRAN.R-project.org/package=MaxPro [Accessed 23 May 2019].

Borge-Diez, D., Colmenar-Santos, A., Mur-Pérez, F., et al., 2013. Impact of passive techniques and clean conditioning systems on comfort and economic feasibility in low-cost shelters. Energy and Buildings, 62, pp.414-426.

Borge-Diez, D., Colmenar-Santos, A., Pérez-Molina, C., et al., 2013. Passive climatization using a cool roof and natural ventilation for internally displaced persons in hot climates: Case study for Haiti. Building and Environment, 59, pp.116-126. 
Chartered Institution of Building Services Engineers, 2013. The limits of thermal comfort: avoiding overheating in European buildings, London: The Chartered Institution of Building Services Engineers.

Chartered Institution of Building Services Engineers, 2017a. Design methodology for the assessment of overheating risk in homes, London: Chartered Institution of Building Services Engineers.

Chartered Institution of Building Services Engineers, 2017b. Environmental Design: CIBSE Guide A 8th ed., London: Chartered Institution of Building Services Engineers.

Clarke, J.A., 2001. Energy simulation in building design 2nd ed., Oxford: Butterworth-Heinemann.

Clarke, J.A. \& Hensen, J.L.M., 2015. Integrated building performance simulation: Progress, prospects and requirements. Building and Environment, 91, pp.294-306.

Cornaro, C. et al., 2015. Thermal performance analysis of an emergency shelter using dynamic building simulation. Energy and Buildings, 88, pp.122-134.

Corsellis, T., 2001. The Selection of Sites for Temporary Settlements for Forced Migrants. Cambridge: University of Cambridge.

Corsellis, T. ed., 2012. Transitional shelter guidelines 1st ed., Geneva: Shelter Centre.

Crawford, C., Manfield, P. \& McRobie, A., 2005. Assessing the thermal performance of an emergency shelter system. Energy and Buildings, 37(5), pp.471-483.

Dalal, A. et al., 2018. Planning the Ideal Refugee Camp? A Critical Interrogation of Recent Planning Innovations in Jordan and Germany. Urban Planning, 3(4), pp.64-78.

Deru, M. et al., 2011. US Department of Energy commercial reference building models of the national building stock, [Online]. Available from: http://digitalscholarship.unlv.edu/renew_pubs/44/?utm_source=digitalscholarship.unlv.edu/re new_pubs/44\&utm_medium=pdf\&utm_campaign=pdfcoverpages [Accessed 7 May 2017].

Félix, D., Branco, J.M. \& Feio, A., 2013. Temporary housing after disasters: A state of the art survey. Habitat International, 40, pp.136-141.

Fosas, D., Albadra, D., et al., 2018. Refugee housing through cyclic design. Architectural Science Review, 61(5), pp.327-337.

Fosas, D., Herrera, M., et al., 2018. Weather files for remote places: leveraging reanalyses and satellite datasets. In 1st International Conference on Data for Low Energy Buildings. 1st International Conference on Data for Low Energy Buildings. Murcia: Diego Marín, Murcia, pp. 14-19.

Fosas, D. et al., 2019. Dataset for 'The importance of thermal modelling and prototyping in transitional shelter design'.

Gelaro, R. et al., 2017. The Modern-Era Retrospective Analysis for Research and Applications, Version 2 (MERRA-2). Journal of Climate, 30(14), pp.5419-5454.

Haigh, S.K., 2012. Thermal conductivity of sands. Géotechnique, 62(7), pp.617-625.

Hamilton, I. et al., 2017. Using epidemiological methods in energy and buildings research to achieve carbon emission targets. Energy and Buildings, 154(Supplement C), pp.188-197. 
Huebscher, R., 1948. Friction equivalents for round, square and rectangular ducts. ASHVE Transactions (Renamed ASHRAE Transactions), 54, pp.101-144.

Hunter, J.D., 2007. Matplotlib: A 2D Graphics Environment. Computing in Science \& Engineering, 9(3), pp.90-95.

Jones, E. et al., 2001. SciPy: Open source scientific tools for Python. [Online]. Available from: http://www.scipy.org/ [Accessed 1 May 2019].

Joseph, V.R., Gul, E. \& Ba, S., 2015. Maximum projection designs for computer experiments. Biometrika, 102(2), pp.371-380.

Kavgic, M. et al., 2010. A review of bottom-up building stock models for energy consumption in the residential sector. Building and Environment, 45(7), pp.1683-1697.

Kendall, M.G., 1938. A New Measure of Rank Correlation. Biometrika, 30(1-2), pp.81-93.

Kibirige, H., 2019. A grammar of graphics for Python. Contribute to has $2 \mathrm{kl} /$ plotnine development by creating an account on GitHub. [Online]. Available from: https://github.com/has2k1/plotnine [Accessed 23 May 2019].

Kluyver, T. et al., 2016. Jupyter Notebooks - a publishing format for reproducible computational workflows. , pp.87-90.

Knight, W.R., 1966. A computer method for calculating Kendall's tau with ungrouped data. Journal of the American Statistical Association, 61(314), pp.436-439.

Kokoska, S. \& Zwillinger, D., 2000. CRC Standard Probability and Statistics Tables and Formulae, Student Edition, Mathematics/Probability, London: CRC.

Kottek, M. et al., 2006. World Map of the Köppen-Geiger climate classification updated. Meteorologische Zeitschrift, 15(3), pp.259-263.

Kruis, N. \& Krarti, M., 2017. Three-dimensional accuracy with two-dimensional computation speed: using the Kiva ${ }^{\mathrm{TM}}$ numerical framework to improve foundation heat transfer calculations. Journal of Building Performance Simulation, 10(2), pp.161-182.

Liddament, M.W., 1996. A guide to energy efficient ventilation, Coventry: The Air Infiltration and Ventilation Centre.

Manfield, P., Ashmore, J. \& Corsellis, T., 2004. Design of humanitarian tents for use in cold climates. Building Research \& Information, 32(5), pp.368-378.

Mantesi, E. et al., 2018. The modelling gap: Quantifying the discrepancy in the representation of thermal mass in building simulation. Building and Environment, 131, pp.74-98.

McKinney, W., 2010. Data Structures for Statistical Computing in Python. In Proceedings of the 9th Python in Science Conference. pp. 51-56.

Monari, F. \& Strachan, P.A., 2017. Calibro an R package for the automatic calibration of building energy models. In Proceedings of Building Simulation 2017.

National Renewable Energy Laboratory, 2018. EnergyPlus ${ }^{T M}$ v9.0.1. [Online]. Available from: https://github.com/NREL/EnergyPlus/releases/tag/v9.0.1 [Accessed 17 May 2019]. 
Obyn, S., van Moeseke, G. \& Virgo, V., 2015. Thermal performance of shelter modelling: Improvement of temporary structures. Energy and Buildings, 89, pp.170-182.

Orme, M., Liddament, M.W. \& Wilson, A., 1998. Numerical Data for Air Infiltration and Natural Ventilation Calculations, Bracknell, Coventry: Air Infiltration and Ventilation Centre.

Paszkiewicz, N. \& Fosas, D., 2019. Reclaiming refugee agency and its implications for shelter design in refugee camps. In Proceedings of the 1st International Conference on: Comfort at the Extremes: Energy, Economy and Climate. International Conference on: Comfort at the Extremes: Energy, Economy and Climate. Dubai: Ecohouse Initiative Ltd, pp. 584-594.

Pedregosa, F. et al., 2011. Scikit-learn: Machine Learning in Python. Journal of Machine Learning Research, 12(Oct), pp.2825-2830.

Perez, F. \& Granger, B.E., 2007. IPython: A System for Interactive Scientific Computing. Computing in Science \& Engineering, 9(3), pp.21-29.

Pöschl, R., 2016. Modelling the thermal comfort performance of tents used in humanitarian relief. Loughborough: Loughborough University. [Online]. Available from: https://pdfs.semanticscholar.org/c40d/d8cd71ddd730fbac11a9422a2556955bd1ef.pdf [Accessed 5 September 2019].

Potangaroa, R. \& Hynds, M., 2008. Thermal Comfort Tools for Emergency Shelter in Major Disasters. In Proceedings from International Conference on Building Education and Research. CIB W89 International Conference on Building Education and Research. Heritance Kandalama: School of the Built Environment, University of Salford, pp. 1457-1472.

Python Software Foundation, 2019. Python 3.7.3. [Online]. Available from: https://docs.python.org/3.7/reference/ [Accessed 23 May 2019].

R Core Team, 2019. R: A Language and Environment for Statistical Computing, Vienna, Austria: R Foundation for Statistical Computing. [Online]. Available from: https://www.R-project.org/.

Roubeyrie, L. \& Celles, S., 2018. Windrose: A Python Matplotlib, Numpy library to manage wind and pollution data, draw windrose. Journal of Open Source Software, 3(29), p.268.

Schroedter-Homscheidt, M. et al., 2017. User's Guide to the CAMS Radiation Service, Reading: Copernicus Atmosphere Monitoring Service. [Online]. Available from: http://atmosphere.copernicus.eu/sites/default/files/FileRepository/Resources/Documentation/ Radiation/CAMS72_2015SC2_D72.1.3.1_2017_UserGuide_v1.pdf [Accessed 1 March 2018].

Spearman, C., 1904. The Proof and Measurement of Association between Two Things. The American Journal of Psychology, 15(1), pp.72-101.

Steadman, R.G., 1979a. The Assessment of Sultriness. Part I: A Temperature-Humidity Index Based on Human Physiology and Clothing Science. Journal of Applied Meteorology, 18(7), pp.861873.

Steadman, R.G., 1979b. The Assessment of Sultriness. Part II: Effects of Wind, Extra Radiation and Barometric Pressure on Apparent Temperature. Journal of Applied Meteorology, 18(7), pp.874-885.

Steadman, R.G., 1984. A Universal Scale of Apparent Temperature. Journal of Climate and Applied Meteorology, 23(12), pp.1674-1687. 
Swami, M.V. \& Chandra, S., 1987. Procedures for Calculating Natural Ventilation Airflow Rates in Buildings, Cape Canaveral, Florida: Florida Solar Energy Center.

Swan, L.G. \& Ugursal, V.I., 2009. Modeling of end-use energy consumption in the residential sector: A review of modeling techniques. Renewable and Sustainable Energy Reviews, 13(8), pp.1819-1835.

Taylor, J. et al., 2016. Mapping indoor overheating and air pollution risk modification across Great Britain: A modelling study. Building and Environment, 99, pp.1-12.

The Sphere project, 2011. Humanitarian Charter and Minimum Standards in Humanitarian Response 3rd ed., Practical Action Publishing. [Online]. Available from: http://www.spherehandbook.org/content/pages/en/8.minimum-standards-inshelter_settlement-and-non-food-items.pdf.

United Nations High Commissioner for Refugees, 2016. Shelter Design Catalogue, Geneva: UNHCR.

United Nations High Commissioner for Refugees, 2017a. Global Report 2017, Geneva: UNHCR.

United Nations High Commissioner for Refugees, 2017b. Statistical Yearbook 2016, Geneva: UNHCR.

United Nations High Commissioner for Refugees, 2019a. UNHCR Population data and key demographical indicator - Bangladesh, Cox's Bazar. [Online]. Available from: https://data2.unhcr.org/en/documents/details/69523 [Accessed 16 May 2019].

United Nations High Commissioner for Refugees, 2019b. UNHCR Statistics - The World in Numbers. popstats.unhcr.org. [Online]. Available from: http://popstats.unhcr.org [Accessed 16 May 2019].

U.S. Department of Commerce, 2019. National Oceanic and Atmospheric Administration. [Online]. Available from: https://www.noaa.gov/ [Accessed 17 May 2019].

Van Wijk, W.R. \& De Vries, D., 1963. Periodic temperature variations in a homogeneous soil. Physics of plant environment, 1, pp.103-143.

VanderPlas, J. et al., 2018. Altair: Interactive Statistical Visualizations for Python. Journal of Open Source Software, 3(32), pp.1-2.

van der Walt, S., Colbert, S.C. \& Varoquaux, G., 2011. The NumPy Array: A Structure for Efficient Numerical Computation. Computing in Science \& Engineering, 13(2), pp.22-30.

Waskom, M., 2018. mwaskom/seaborn: v0.9.0 (July 2018). [Online]. Available from: https://zenodo.org/record/1313201 [Accessed 23 May 2019].

de Wilde, P., 2014. The gap between predicted and measured energy performance of buildings: A framework for investigation. Automation in Construction, 41, pp.40-49.

de Wit, S. \& Augenbroe, G., 2002. Analysis of uncertainty in building design evaluations and its implications. Energy and Buildings, 34(9), pp.951-958.

Yacout, G., Almomani, H. \& United Nations High Commissioner for Refugees, 2018. Jordan Factsheet: Azraq Refugee Camp (December 2018), Jordan: UNHCR. [Online]. Available from: https://reliefweb.int/report/jordan/unhcr-jordan-factsheet-azraq-refugee-camp-december-2018 [Accessed 17 May 2019]. 
Yu, Y. et al., 2016. Assessing the Thermal Performance of Temporary Shelters. Procedia Engineering, 159, pp.174-178. 